Report No. BMI-1141 Engineering

(TID-4500, 12th Ed.)

Contract No, W-7405-eng-92

\title{
STUDIES OF FLOW DISTRIBUTION IN THE CORE OF A QUARTER-SCALE FLOW MODEL \\ OF THE PWR REACTOR
}

by

Herbert R. Hazard

John M. Allen

October 19, 1956

BATTELLE MEMORIAL INSTITUTE

$505 \mathrm{~K}$ ing Avenue

Columbus 1, Ohio 


\section{DISCLAIMER}

This report was prepared as an account of work sponsored by an agency of the United States Government. Neither the United States Government nor any agency Thereof, nor any of their employees, makes any warranty, express or implied, or assumes any legal liability or responsibility for the accuracy, completeness, or usefulness of any information, apparatus, product, or process disclosed, or represents that its use would not infringe privately owned rights. Reference herein to any specific commercial product, process, or service by trade name, trademark, manufacturer, or otherwise does not necessarily constitute or imply its endorsement, recommendation, or favoring by the United States Government or any agency thereof. The views and opinions of authors expressed herein do not necessarily state or reflect those of the United States Government or any agency thereof. 


\section{DISCLAIMER}

Portions of this document may be illegible in electronic image products. Images are produced from the best available original document. 
TABLE OF CONTENTS

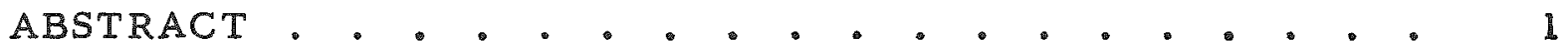

INTRODUCTION •. . . . . . . . . . . . . . 1

SUMMARY AND CONCLUSIONS . . . . . . . . . . 1

DESCRIPTION OF QUARTER-SCALE FLOW MODEL . . . . . 2

General Description . . . . . . . . . . . 2

Description of Flow-Model Core . . . . . . . . 6

Model Setup and Operation . . . . . . . . . . 9

HYDRODYNAMIC DESIGN OF MODEL •. . . . . . . 10

Comparison of Model-Flow Conditions With

Prototype-Flow Conditions . . . . . . . . . 10

SUMMARY OF DATA FROM CORE-FLOW STUDIES OF

QUARTER-SCALE FLOW MODEL . . . . . . . . . 13

Distribution of Flow Among Core Regions . . . . . . 13

Distribution of Pressure Losses Throughout 13

Sequence of Model Alterations, Internal-Orifice

Calibrations, and Core Tests . . . . . . . 15

Core-Flow-Distribution Data . . . . . . . . . . 17

RECOMMENDATIONS . . . . . . . . . . . . . . 44

Additional Studies in the Quarter-Scale Model. . . . . . 44

Future Model Design . . . . . . . . . . . . 44

ACKNOWLEDGMENTS

\section{APPENDIX}

CORRECTION FACTORS FOR MEASURING ORIFICES

IN CORE OF QUARTER-SCALE FLOW MODEL OF THE

PWR REACTOR 


\title{
SIUDIES UF FLUW DISTRIBUTION IN THE CORE OF A QUARTER-SCALE FLOW MODEL OF THE PWR REACTOR
}

\author{
Herbert R. Hazard and John M. Allen
}

\begin{abstract}
Distribution of flow among fuel clusters in a quarter-scale flow model of the PWR recator was studied using air flow to simulate coolant flow. Under all power-plant operating conditions the flow through all clusters was within 3 per cent of the average flow for the region in which the cluster was located.
\end{abstract}

\section{INTRODUCTION}

This report presents data on flow distribution in the core of a quarterscale flow model of the PWR reactor that is being designed at the Bettis Laboratory of the Atomic Energy Commission, operated by the Westinghouse Electric Corporation. The flow model was designed at the Bettis Laboratory and built at the Aviation Gas Turbine Division of Westinghouse. This is the first of several flow studies conducted at Battelle using this model. Other studies are to be covered in similar topical reports.

Air-flow studies of the quarter-scale model of the PWR reactor have been used to evaluate and prove the adequacy of the flow baffle, which affects distribution of coolant flow throughout the reactor core. The flow distribution within the core and the variation of this flow distribution with the number of power loops used are of importance because variations in coolant flow result in corresponding variations in coolant temperatures at cluster outlets. As heat transfer from the core is limited by the maximum coolant temperatures, it is es sential that peak temperatures should be close to the mean temperature.

\section{SUMMARY AND CONCLUSIONS}

Several groups of tests were run in the quarter-scale flow model, with minor changes in the model between tests. In preliminary tests, it was found that rather large variations in flow distribution were occurring in the model as the result of differences in coefficients of nominally identical orifices and leakage through rubber gaskets. After several trials, flowmeasuring orifices were accurately calibrated and gaskets adequately sealed. 
The results of the final tests showed that the original design of the flow baffle was adequate, as the variations in flow among clusters in each zone were less than 3 per cent under all operating conditions, except for two clusters for which data could be shown to be consistently in error as the result of physical factors in the clusters.

The variations actually measured were not readily related to differences in flow conditions resulting from changes in operation, but appeared to be the result of differences in coefficients of uncalibrated inlet orifices.

Test data could be reproduced within 0.3 per cent in successive tests, showing that the reliability of the data is high.

\section{DESCRIPTION OF QUARTER-SCALE FLOW MODEL}

\section{General Description}

The quarter-scale flow model was designed to simulate flow conditions throughout the PWR reactor with the exception of those within the fuel as semblies; these were simulated with orificed tubes having proper flow resistances. It was constructed of aluminum and stainless steel throughout, except for the upper and lower domes, which were constructed of glassfiber-reinforced plastic. The model was designed at the Bettis Laboratory of the Atomic Energy Commission, operated by the Westinghouse Electric Corporation, and was constructed by the Aviation Gas Turbine Division of Westinghouse. Internal instruments were supplied with the model, and external instruments were added at Battelle.

Figure 1 is a photograph of the quarter-scale flow model set up for tests. Four blowers at the left supplied air for tests and the large manometer board at the right was used to record pressures throughout the model. The highest air flow used in the quarter-scale model was $5.33 \mathrm{lb}$ per sec at 5.2 psi.

Figure 2 is a vertical section of the quarter-scale flow model showing the general arrangement of the pressure shell, the inlets and outlets, the thermal shields, the flow baffle, the core, the control-rod guides, the holddown barrel, and the internal instrumentation.

Figure 3 is a horizontal section of the model showing arrangement of the thermal shields, the core fuel clusters, and the shield-passage instrumentation. 




FIGURE 1. PHOTOGRAPH OF QUARTER-SCALE FLOW MODEL OF PWR REACTOR INSTALLED FOR AIR-FLOW STUDIES 


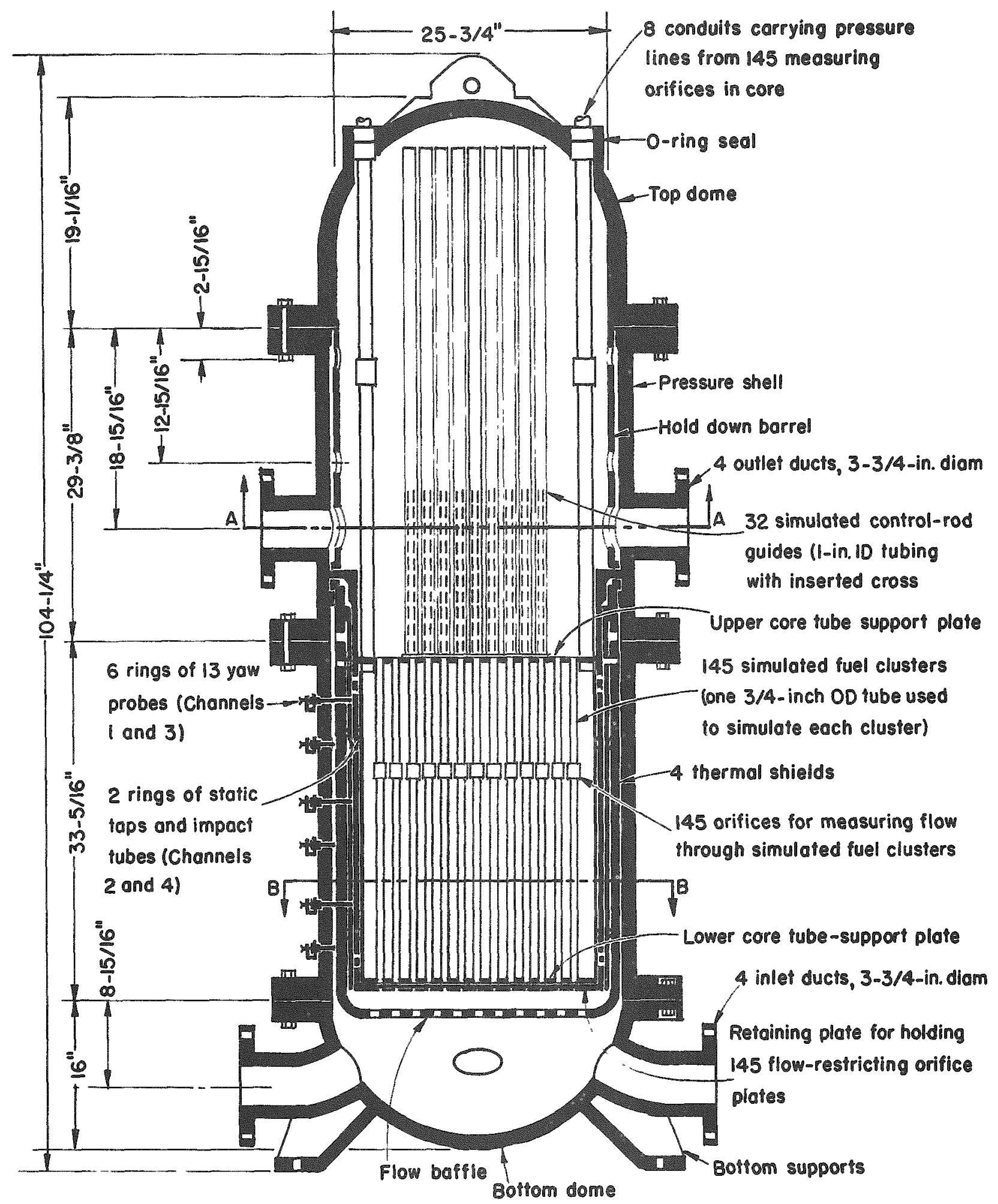

FIGURE 2. QUARTER-SCALE FLOW MODEL OF PWR REACTOR VERTICAL SECTION 




FIGURE 3. QUARTER-SCALE FLOW MODEL OF PWR

REACTOR - HORIZONTAL SECTION

THROUGH CORE 
Figure 4 is a photograph of the flow baffle used in the model. The baffle was constructed of cast aluminum $3 / 8$ in. thick, and drilled with 445 holes of $0.550-i n$. diameter. After preliminary tests the outermost ring of 24 holes was plugged, leaving 421 holes.

Air, simulating the coolant, entered through two or more of the inlets at the bottom of the model. About 85 per cent of the coolant flowed upward through the perforated flow baffle under the core; the baffle pressure drop was designed to force about 15 per cent of the coolant through the thermalshield passages at the outer periphery of the model. Coolant from these parallel paths mixed below the core, then passed upward through the core. In the model, the core fuel clusters were simulated by round tubes, each containing an orifice for measurement of flow through the tube and a restricting orifice at the tube inlet for control of flow. The core was divided into five regions. Flow through all fuel assemblies in each region is equal but flow to different regions differed. Above the core is a large plenum space through which the control-rod guides passed, and a hold-down barrel containing 28 holes through which coolant must pass to reach the four outlets.

\section{Description of Flow-Model Core}

The model core contained 145 simulated fuel clusters, of which 32 simulated enriched seed clusters and 113 simulated unenriched blanket assemblies. These were arranged in regions, as shown in Figure 3 , such that the annular seed region was surrounded by annular blanket regions. Coolant flow was designed to be proportional to heat flux in the prototype, and was highest in the seed region, lower in Regions 2 and 3 , and lowest in Regions 1 and 4. All clusters within one zone were designed for equal flow.

Each simulated fuel cluster in the flow model consisted of a $3 / 4-i n . O D$ tube having a flow-measuring orifice installed near the upper end, as shown in Figure 2. All orifices in each region were of the same diameter but orifices in different regions were of different diameters. In addition to the flow-measuring orifice, each tube had an inlet orifice for additional restriction of flow. These orifices were recessed into a large plate which was bolted to the bottom of the core assembly so that each orifice was accurately aligned with a core tube. The flow through each core tube depended upon the combined resistances of the flow-restricting orifice and the measuring orifice. The two orifices in each tube had similar pressure drops, except for those in the seed region where the inlet orifice was slightly larger than the tube diameter and most of the pressure drop was taken at the measuring orifice.

Figure 5 shows the construction of the orifice-retaining plate. This plate was bolted to the bottom of the core and sealed with a rubber gasket. Each orifice plate was held in place by two small screws and sealed with a rubber gasket, as shown. 


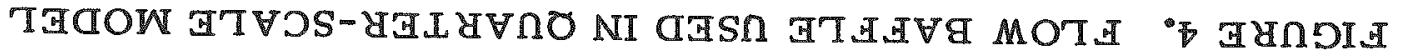

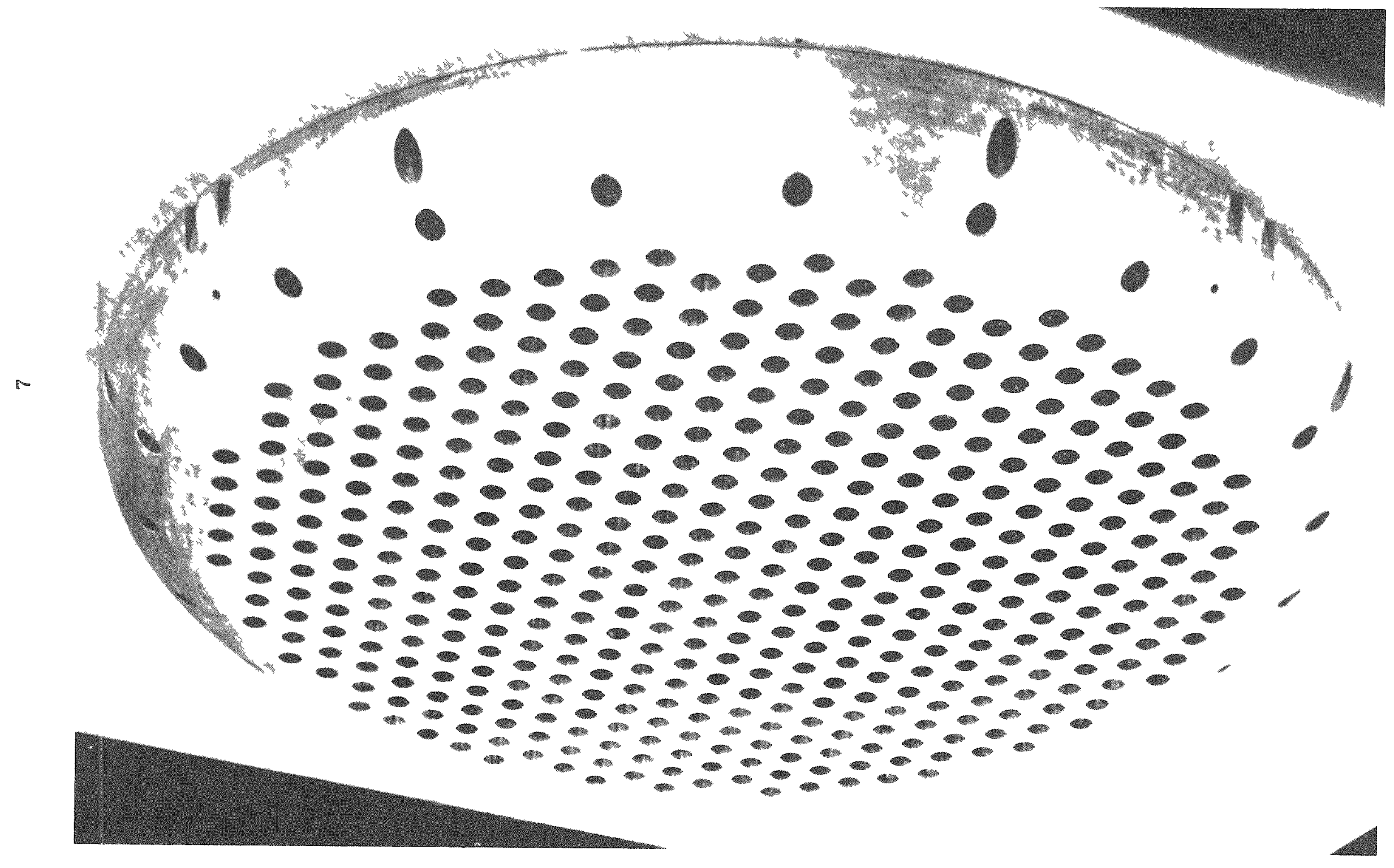




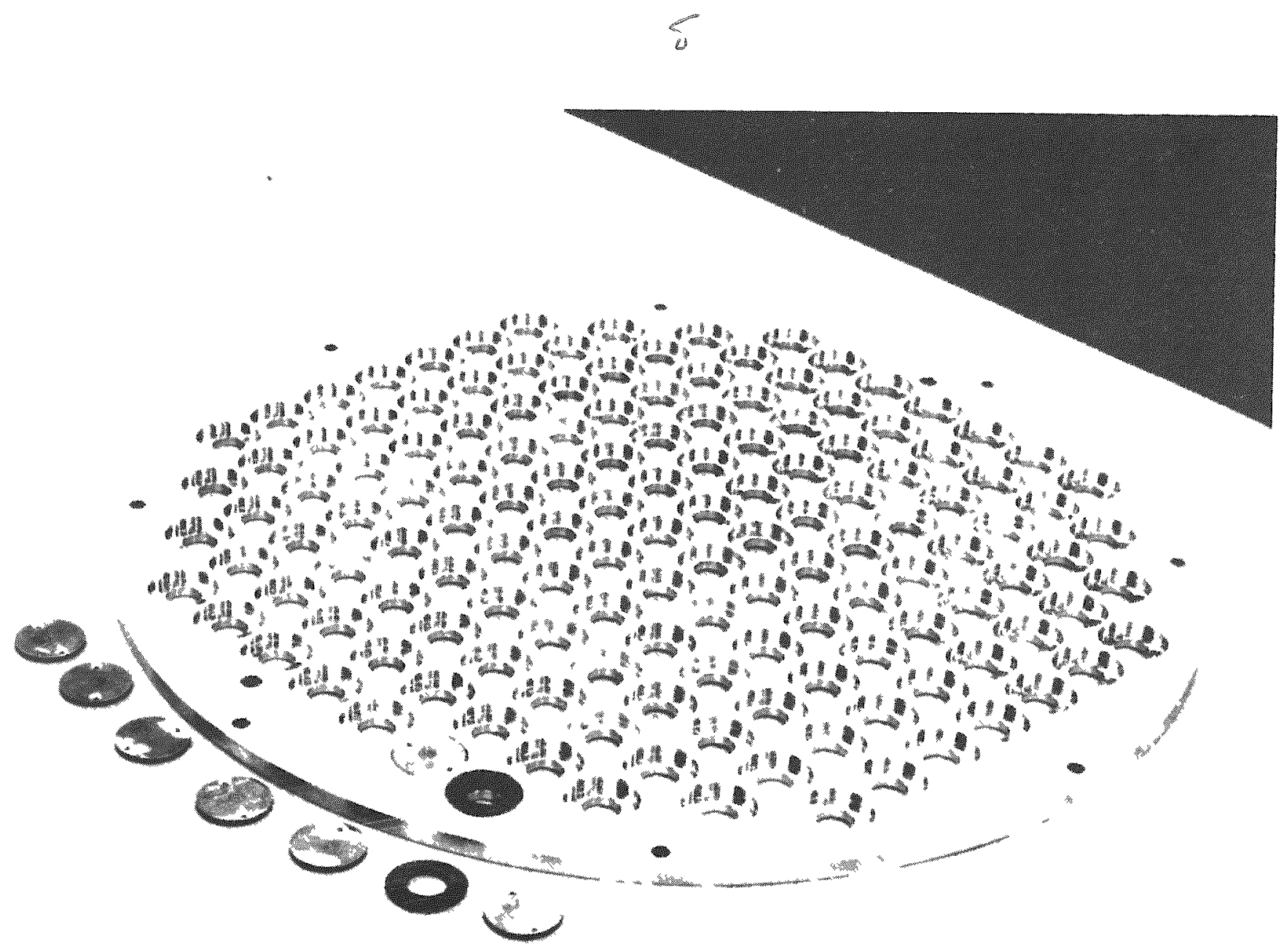

FIGURE 5. RETAINING PLATE AND FLOW-RESTRICTING ORIFICES USED AT CORE INLETS 
Model Setup and Operation

The model was set up so that inlet and outlet conditions and flow conditions could be closely controlled. Details of piping and external instrumentation may be seen in Figure 1.

The model was installed with $90-$ deg elbows on each inlet to simulate prototype installation. A flow-measuring nozzle was installed at each inlet to measure flow and to determine when flow through inlets was equalized. Flow to individual inlets was adjusted by inserting or retracting $3 / 8$-in. rods into the air streams in the elbows. Only a small amount of adjustment was necessary because of the high air velocities at the inlets. The approach piping, carrying air at pressures to 6 psi and temperatures to $190 \mathrm{~F}$, was constructed with turning vanes in elbows to minimize flow disturbances approaching the inlet nozzles.

For core and shield studies, the outlets were discharged to the room through tubes 10 diameters long. Flow through the outlets was equalized by varying the insertion of $3 / 8-i n$. rods until impact pressures at the outlet ends of the outlet pipes were equal.

In tests with simulated operation of less than four loops, plates were installed between flanges at inactive inlets and outlets.

Pressure taps from the 145 measuring orifices in the core and staticpressure taps in the lower plenum, upper plenum, and shield regions were connected to a specially constructed manometer board having 360 tubes, each suitable for measurement of pressures up to $170 \mathrm{in}$. of water. The manometer board consisted of six well-type manometers, each having one leveling tank and many manometer tubes. Each manometer tube extended from the model to the top of the manometer, then passed down through the manometer and was connected to a header at the bottom. Manometer tubes were of translucent polyethylene plastic. In use, pressure depressed the level of the water in individual manometer tubes, and the tank levels were adjusted to suitable heights for ease of reading. Each tank level showed on one manometer tube, and measured pressures were the differences in height between this level and the reading of each tube in the manometer. Orifice differentials and reading accuracy we re such that flow measurements could be reproduced to approximately \pm 0.3 per cent. 
HYDRODYNAMIC DESIGN OF MODEL

Comparison of Model-Flow Conditions With Prototype-Flow Conditions

In making model studies of flow, it is desirable to have dynamic similarity of model and prototype to insure that data from the model will exactly check with data from the prototype, Dynamic similarity is achieved when the Reynolds number for flow in the prototype is equal to the Reynolds number for flow in a geometrically similar model.

For equal scale and velocity, the Reynolds number for water under PWR reactor conditions would be about 116 times that for air under model test conditions. In the quarter-scale flow model, air velocities were about 6. 9 times prototype water velocities which, with the reduced scale, resulted in Reynolds numbers $1 / 67$ those in the prototype. Under 3-loop test conditions, the Reynolds number in the model inlet ducts which is representative of Reynolds numbers in upper and lower plenum regions, was about 400,000, compared to a prototype value of 30,000,000. However, in thermal shield coolant passages, model Reynolds numbers as low as 6500 occurred. Reynolds numbers were sufficiently high that dynamic similarity was approached in all regions except the thermal shield coolant passages. In these passages, low Reynolds numbers resulted in excessive friction loss. Accordingly, the flow-restricting orifices in the shield passages were made somewhat oversize, reducing momentum losses to compensate for excessive friction loss, so that total pressure loss and total flow through the shield passages would equal those which would have occurred with dynamic similarity. With this modification, the influence of shield flow on other regions in the model would be the same as for dynamic similarity, although flow conditions within the shield passages would be somewhat different than for dynamic similarity.

Because of low values of Reynolds number in thermal shield coolant passages and because of changes in the prototype shield design, data on pressure losses in shield passages of the quarter-scale model were not used for design purposes. Instead, a 1.5-scale model of a section of the shield passages, giving Reynolds numbers up to 500,000 , was used.

The internal design of the model core was not scaled from the prototype, but was simulated by round tubes containing orifices designed to provide core flow distribution and pressure drop equal to those which would be obtained with dynamic similarity. Thus, although dynamic similarity was not achieved within the core structure, the effects on other components of the model were the same as those which would occur with dynamic similarity. 
The pressure drop across the model was as high as 5.25 psi, resulting in a 26 per cent change of air density from model inlets to model outlets. This pressure loss was concentrated in the core, the inlets, and the outlets so that density changes in the upper and lower plenum regions and in the thermal shield passages were negligible. The density change within the simulated core influenced the design of core orifices, but did not otherwise affect model design or operation. Thus, compressibility corrections were not required in studies of flow baffle performance and distribution of flow in the core. However, for any comparisons including both lower-plenum and upper-plenum pressure data, isothermal compressibility corrections would be used.

For an incompressible fluid, the ratio of the core pressure loss to any other differential in the reactor would provide a suitable basis for comparison of the prototype with a model. For air with a density change of 26 per cent, however, ratios of core pressure loss to lower plenum pressure differentials would be different from ratios with upper plenum pressure differentials or with over-all pressuredrop for the reactor. Because an important part of the model study was to relate lower plenum momentum parameters to the distribution of flow through the core, the core pressure drop was expressed as the ratio of core pressure drop to velocity pressure in the inlet ducts and the same ratio was used for both the prototype and the model. That is, for four-loop conditions

$$
\frac{p_{2}-p_{3}}{q_{i}} \text { for the prototype was made equal to } \frac{p_{2}-p_{3}}{q_{i}} \text { for the model, }
$$

where:

$$
\begin{aligned}
& p_{2}=\text { static pressure below the core, psi } \\
& p_{3}=\text { static pressure above the core, psi } \\
& q_{i}=\text { velocity pressure in inlet ducts, psi: } \\
& \qquad q_{i}=\frac{V_{i}^{2}}{(2 g) 144}=\text { psi } \\
& V_{i}=\text { coolant velocity in the inlet ducts. }
\end{aligned}
$$

A reduction in the number of operating loops would result in a decrease in the core pressure drop and an increase in the inlet velocity, so that values of $\left(p_{2}-p_{3}\right) / q_{1}$ would vary from about 10 for four-loop flow to about 2. 4 for two-loop flow.

With the core pressure differential established for dynamic similarity, orificing was designed to provide the required flow resistance through each tube in the core assembly. The pressure differential was 
divided between two orifices, one in the tube, used for flow measurement, and one at the tube inlet, used for additional flow restriction. All blanketregion measuring orifices were designed to provide a pressure differential of 48 in. water with proper flow distribution under four-1oop operating conditions. The seed flow was much higher, so it was necessary to design for a measuring differential of 103 in. water.

After preliminary design, sample orifices were made and calibrated in a test rig which held one core tube fitted with orifices in the configuration used in the model. In calibration, it was found that flows were somewhat different than calculated values because of the difficulty in estimating recovery of pressure following each orifice. The diameters of the inlet orifices were altered and the assembly was recalibrated until correct flow resistance was obtained. Final values as determined by the calibrations were used in the model. The nominal diameters of orifices in the core assembly are shown in Table 1.

TABLE 1. NOMINAL DIAMETERS OF CORE ORIFICES FOR PWR FLOW MODEL

\begin{tabular}{ccc}
\hline \hline & \multicolumn{2}{c}{ Diameter, in. } \\
\cline { 2 - 3 } Region & $\begin{array}{c}\text { Measuring } \\
\text { Orifice }\end{array}$ & $\begin{array}{c}\text { Flow-Restricting } \\
\text { Orifice }\end{array}$ \\
\hline 1 & 0.393 & 0.304 \\
2 & 0.511 & 0.426 \\
3 & 0.490 & 0.407 \\
4 & 0.338 & 0.258 \\
Seed & 0.586 & 0.704 \\
\hline
\end{tabular}

Although the diameters of all orifices in the model core were held within \pm 0.0005 in of specified diameter, it was found that when orifices were calibrated under identical flow conditions, the coefficients for orifices within each region varied by as much as 2.5 per cent from the mean coefficient for the region. This variation was assumed to be the result of geometric differences in orifices such as rounding of orifice edges and tool marks. Flow-measuring orifices were calibrated in place, removing orifice coefficients as a source of error in measuring flow rates through simulated clusters. However, these calibrations did not correct for difference in flow rates which occurred because of differences in flow resistance of the calibrated orifices, and of additional differences in resistance which could also result from variations in coefficients of uncalibrated flow-restricting orifices. 
SUMMARY OF DATA FROM CORE-FLOW STUDIES

OF QUARTER-SCALE FLOW MODEL

Core-flow studies were run to determine the distribution of flow throughout the model core, and to detect any variations of flow distribution resulting from changes in the number of simulated loops in operation. In general, it was found that the orificing in the model core provided approximately the desired distribution of flow among the four blanket regions and the seed region, and that flow through each simulated cluster varied by less than 3 per cent from average flow for the region in which it was located. This variation included both the variations resulting from changes in the number and orientation of loops in operation, and the variations of coefficients of measuring and flow-restricting orifices in each cluster.

\section{Distribution of Flow Among Core Regions}

Table 2 is a summary of model test results, in which distribution of flow and pressure loss in the model is compared with specified values for the prototype reactor. It will be noted that values of Item 9, core pressure loss expressed in terms of inlet velosity pressure, are approximately correct in the model for four-loop operating configuration, but are less than the prototype values for two-loop and three-loop configurations. Part of this difference is caused by variations in pressure loss across the flow baffle under the model core. Orifice area coefficients for the 421 orifices in this baffle were found to vary from 0.59 to 0.85 with changes in the number of inlets used, as the result of variations in inlet velocities. This has a large effect on flow through the thermal shield coolant passages, and is to be analyzed in detail in a forthcoming report on flow studies in the shield passages.

The distribution of flow to the core regions was approximately correct, with flow slightly low in Regions 1 and 4, which are the regions of lowest flow; and slightly high in Regions 2 and 3 . The distribution of flow in core regions was not affected by changes in the number of loops in operation.

Distribution of Pressure Losses Throughout Flow Model

Table 3 summarizes static pressures in the quarter-scale flow model for two-loop, three-loop, and four-loop operation. 
TABLE 2. COMPARISON OF FLOW IN QUARTER-SCALE FLOW MODEL WITH THAT IN PROTOTYPE

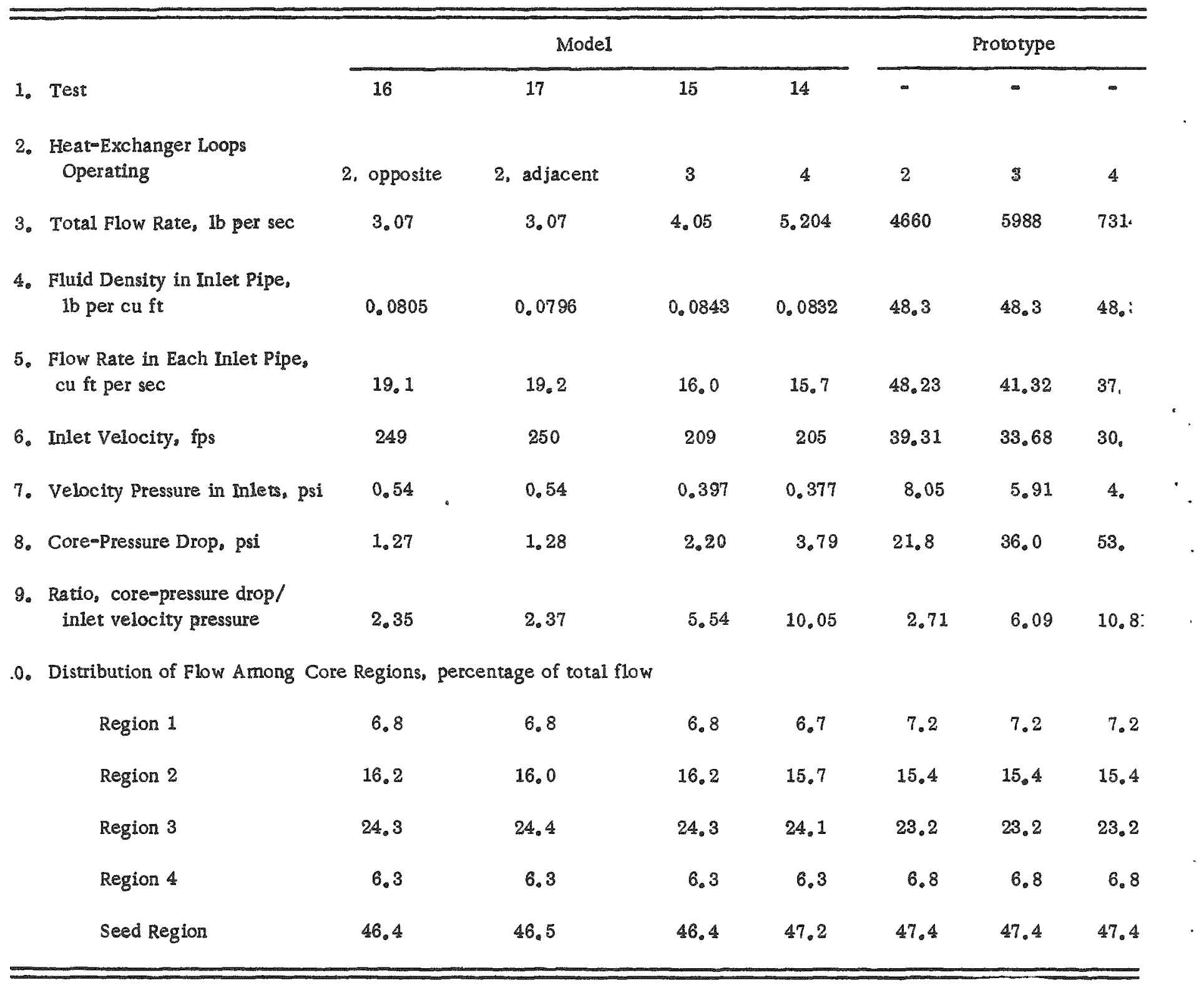


TABIE 3. STATIC PPESSUPES INT QUAPTER-SCALE, FLOW MODEL

Ambient Pressure: 33.40 Ft Water

\begin{tabular}{lccc}
\hline Number of Operating Loops & \multicolumn{1}{c}{$\begin{array}{c}16 \\
\text { Test No. }\end{array}$} & $\frac{16}{4}$ & $\frac{7}{14}$ \\
\hline In inlet pipe & 6.67 & 7.77 & 11.56 \\
Lower plenum space & 5.05 & 6.68 & 10.56 \\
Thermal shield, Channel 1 & 5.06 & 6.47 & 10.52 \\
Thermal shield, Channel 2 & 4.90 & 6.66 & 10.32 \\
Thermal shield, Channel 3 & 4.96 & 6.51 & 10.40 \\
Thermal shield, Channel 4 & 4.94 & 6.57 & 10.38 \\
Above flow baffle & 4.87 & 6.56 & 10.28 \\
Above core & 1.94 & 1.53 & 1.53 \\
Total pressure in outlet ducts & 1.09 & 1.08 & 1.09 \\
Static pressure in outlet ducts & 0.0 & 0.0 & 0.0 \\
\hline
\end{tabular}

Sequence of Model Alterations, Internal-Orifice Calibrations, and Core Tests

The quarter-scale flow model was put into service on April 19, 1956, and complete test data were obtained in Tests 1,2,3,4, and 5. Analysis of core data showed large variations in flow among simulated clusters within each region, with the variations consistent regardless of inlet conditions. An orifice pressure tap in Cluster 87 was found to be plugged, so measurements could not be made in this cluster.

Following Test 5, the model was disassembled, and it was found that many of the flow-restricting orifices at the bottom of the core had rounded edges. All of these orifices were refaced on a lathe to provide identical sharp edges, and thus reduce the variation in orifice coefficients. Diameters were also checked, and found to vary no more than 0.0005 in. from specified diameters.

At the same time it was decided that flow-measuring orifices within the core structure should be calibrated. During this calibration, which was started with the bottom orifice-retaining plate in place (the plate shown in Figure 5), it was found that the large gasket sealing the bottom retaining plate to the bottom tube-support plate of the core permitted leakage transversely from each tube to adjacent tubes. The plate was removedand orifice calibrations were completed. In calibration, air metered by a master orifice was piped into each simulated cluster in the model, and the reading of the measuring orifice was observed on the manometer panel. The calibrations were identified as Test 6. 
When the model was reassembled, the orifice-retaining plate was sealed to the bottom core tube-support plate with Permatex, a soft sealant frequently used for such purposes. It was believed that this would prevent transverse air leakage between simulated clusters. However, in service with air temperatures up to $190 \mathrm{~F}$, the sealant melted and flowed up into the core tubes, fouling flowmeasuring orifices. This became apparent on May 24 during analysis of data from Tests 7, 8, 9, and 10.

The model was again opened, and a calibration of flow-measuring orifices was made with the Permatex as found. The data from Tests 7, 8, 9, and 10 were not materially improved by this calibration, however, as the Permatex apparently changed configuration from test to test. The bulk of the Permatex was removed by use of ramrods with swabs and solvent, and Tests 11, 12, and 13 were run on June 6. However, results of these tests were also erratic.

On June 7 , the model was again opened, and further modifications were made. The Permatex remaining on the faces of some orifices was completely removed with rotary wixe brushes and rotary scrapers driven by an electric drill, followed by swabs and solvent. Since this treatment could dull the edges of measuring orifices, a complete new calibration was run. This calibration was repeated three times to check reproducibility. Values of all orifice correction factors were reproduced within 0.3 per cent in the three calibrations.

In assembling the model, the firm rubber gasket sealing the orificeretaining plate to the bottom core tube-support plate was again used.

Tests 14, 15, 16, and 17 were run on June 14. Data from all regions except Region 4 appeared excellent. Data from Region 4 were erratic. Up to this point, an in-place calibration of flow-restricting orifices mounted on the bottom retaining plate had not been attempted. A calibration rig incorporating a pipe somewhat larger than a flow-restricting orifice plate, with provision for pressing it tightly around the plate in place, was built. The contact surface was sealed with an O-ring.

Before this calibration of Region 4 was started, the firm rubber gasket sealing the orifice-retaining plate to the bottom core tube-support plate was replaced with a soft sponge-rubber gasket, from which all excess rubber had been removed to minimize compression forces. This gasket compressed well in installation and provided satisfactory sealing.

When calibration was started, it was found that leakage could also occur between the orifices and the orifice-retaining plate. The rubber gaskets used to seal these surfaces were rather thin and firm, and the small orificeretaining screws did not provide sufficient force to compress them. Accordingly, the orifice gaskets in Region 4 were replaced with thin sponge-rubber 
gaskets and a calibration was completed with the inlet orifices in place. The combination of good orifice sealing and complete orifice calibration resulted in excellent data for Tests 19, 20, and 21 on June 27. In these tests, data were taken for Region 4 only. Data from these tests were used to replace erratic data for Region 4 in Tests 14, 15, and 16.

Data obtained at this point showed flow variations within regions to be within \pm 3 per cent. Two subassemblies were consistently high, about 5 per cent and 4 per cent above the average for the region in which they were installed. Aside from these two points, which were assumed to result from model geometry, only three test points were found in four tests in which flow varied more than 3 per cent from average flow in each region. In these three clusters, flow varied from the average for the zone by $3.2,3.7$, and 5.0 per cent, respectively, and the 5.0 per cent value was demonstrated to be the result of orifice-gasket leakage.

Test 18 was a special test to determine the reproducibility of model test- and data-analysis procedures. Four tests were run under identical conditions, and for each test a different engineer read the manometers, recorded the data, and completed the data calculations. Comparison of final data plots showed that most points were reproduced four times within a spread of 0.2 per cent, and over 99 per cent of the points were reproduced within 0.3 per cent. The greatest variation, on one point out of 580 , was 1 per cent.

The general construction of the quarter-scale model, as supplied to Battelle, was excellent. The difficulties in obtaining satisfactory data reflect the extreme care which is required when accuracy of flow measurement well within 1 per cent is required. It was concluded that, in the design and construction of any future models for reactor-flow studies, it should be considered essential to calibrate all flow-measuring orifices in place, either during the construction period or at the beginning of the test period.

It is probable that the spread in flow distribution among individual fuel clusters shown in tests described in this report is largely the result of differences in uncalibrated flow-restricting orifices, and of leakage between flow-restricting orifices and the retaining plate. It is planned to replace orifice gaskets throughout the core with sponge rubber, and to calibrate all flow-restricting oxifices in place at a future time, so that small effects resulting from changes in the number of inlets in operation can be observed.

\section{Core-Flow-Distribution Data}

The core-flow-distribution data discussed below were obtained during seven tests. Four of these, Tests 14, 15, 16, and 17, were the basic tests to study the effects of reactor operation with various combinations of loops in operation. In these tests, however, the data from Region 4 were erratic. 
Accordingly, data for Region 4 only were obtained in Tests 19, 20, and 21, after calibrations of inlet orifices and replacement of orifice gaskets with sponge rubber. The data reported for each operating condition are as follows:

\begin{tabular}{|c|c|c|}
\hline Operating Condition & Test & Region 4 Data \\
\hline Four-loop flow & 14 & 21 \\
\hline Three-loop flow & 15 & 19 \\
\hline $\begin{array}{l}\text { Two-loop flow, using } \\
\text { opposite loops }\end{array}$ & 16 & 20 \\
\hline $\begin{array}{l}\text { Two-loop flow, using } \\
\text { adjacent loops }\end{array}$ & 17 & None \\
\hline
\end{tabular}

Figure 6 is a plan view of the core showing the identification numbers of simulated fuel clusters, and the arrangement of seed and blanket regions.

Figure 7 is a map of the core in which each cluster location is marked with the value of flow through that cluster for four-loop flow. Flow is expressed as the percentage of the average mass flow through the region in which the cluster is located. In this data plot, only three points (crosshatched) vary by more than 3 per cent from the average flow in each region. Two of these, at Cluster 126 and Cluster 103, are consistently high in all tests, and it is assumed that this results from inlet-orifice coefficients different from the average, or from leakage through the gasket which seals the inlet orifice to the retaining plate. The third high value, at Cluster 66 , is high only in this test. It was observed that this value was close to 100 per cent at lower flows but that, as flow was increased and pressure drop across the inlet orifices increased, the reading for this cluster suddenly increased. This is undoubtedly the result of orifice-gasket leakage, and the data should be discounted. All other data points fell within 3 per cent of average mass flow for the region, which is better than the tolerance of 7 per cent assumed in original design of the prototype. Data were not obtained for Cluster 87 because an orifice pressure tap was plugged.

Figure 8 is a map of the core showing flow distribution with three-loop flow, from Tests 15 and 19 . In Cluster 20, flow is 3.2 per cent below the average for Region 1, and the usual high values for Clusters 103 and 126 recur. Otherwise, flow through every cluster falls within 3 per cent of the average flow for each region.

Figure 9 is a map of the core showing flow distribution with two opposed loops in operation, using data from Tests 16 and 20 . The two loops used for Test 16 were not the same loops used for Test 20, but the effect of this is not apparent in studying test data. In this test, flow for each cluster was within 3 per cent of the average flow for the region, except for the usual high values for Clusters 103 and 126. 


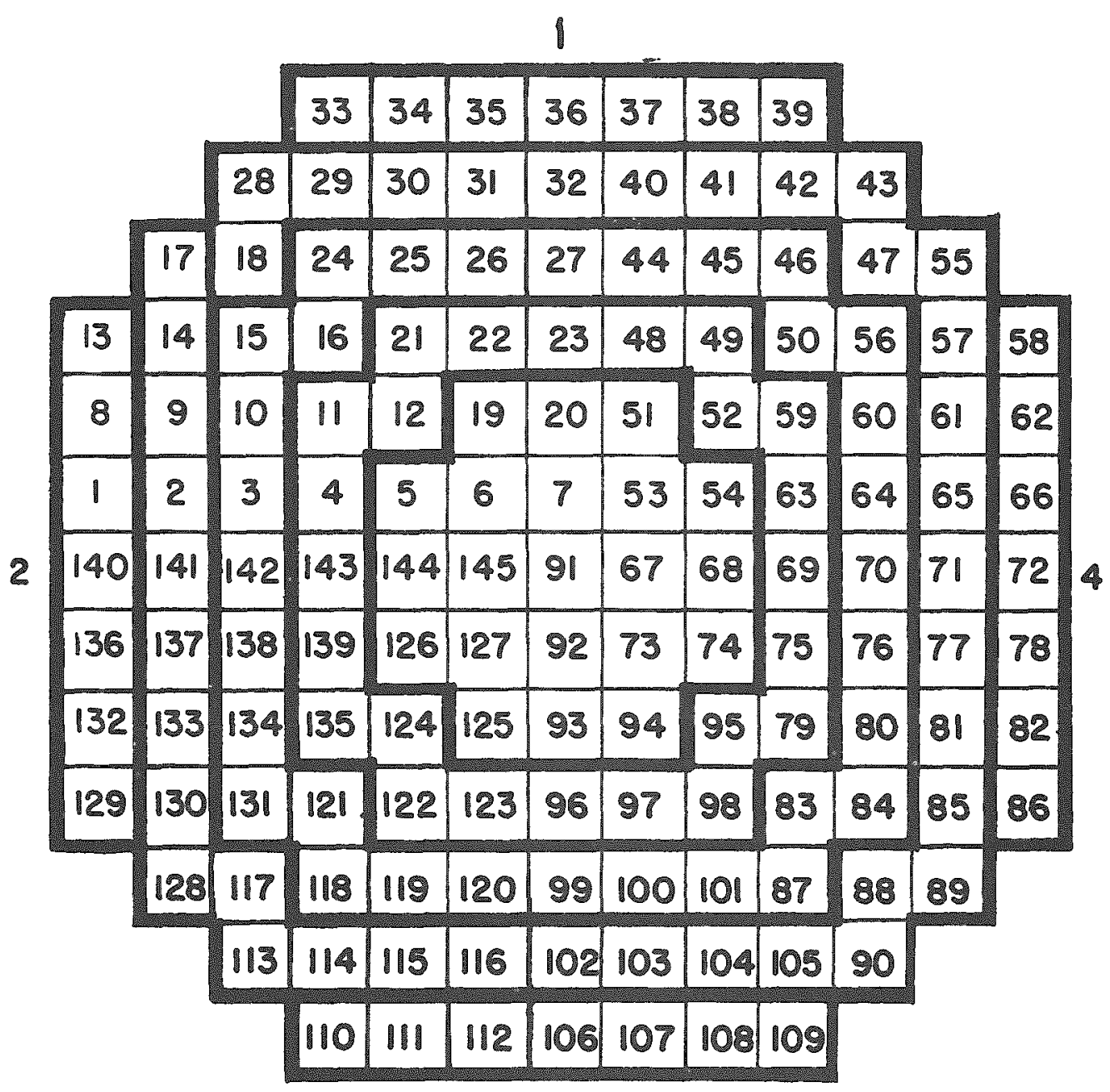

3

FIGURE 6. LOCATIONS OF SIMULATED FUEL CLUSTERS IN CORE OF QUARTERSCALE FLOW MODEL 


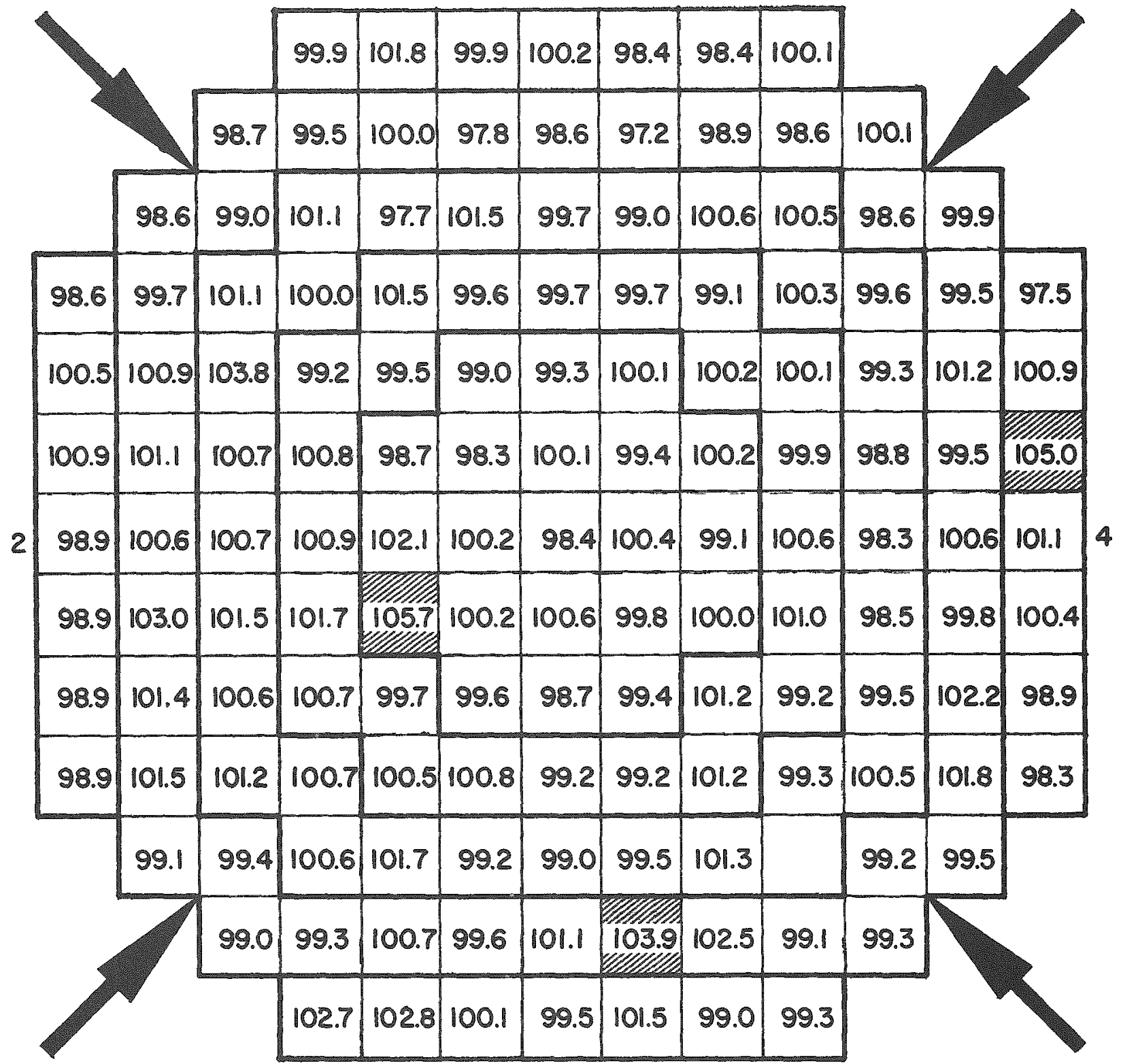

FIGURE 7. FLOW TO EACH FUEL CLUSTER IN MODEL CORE FOR 4-LOOP OPERA TION Expressed as percentage of average flow for region. 




FIGURE 8. FLOW TO EACH FUEL CLUSTER IN MODEL CORE FOR 3 -LOOP OPERATION 


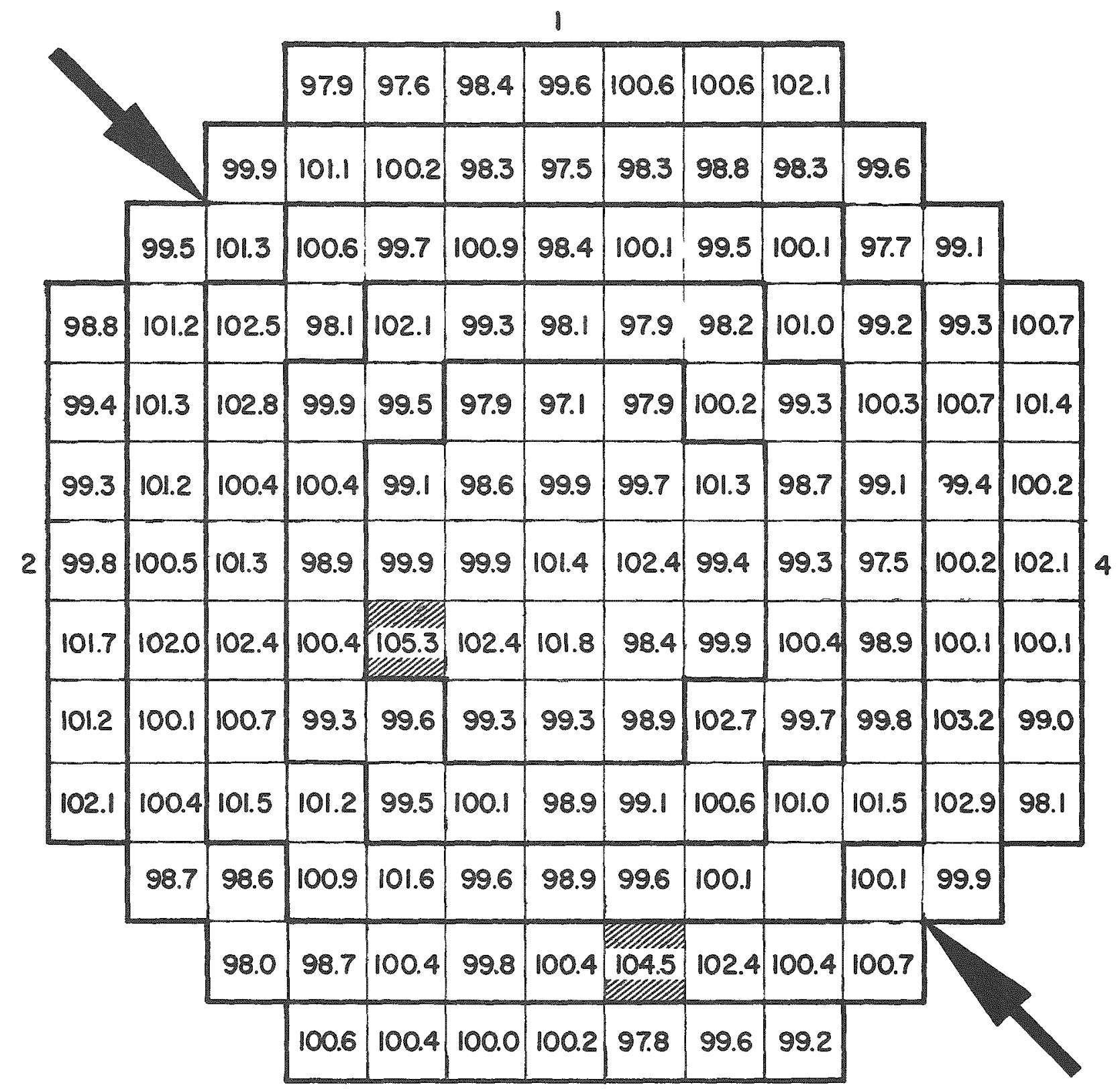

$\times 4746-8$

FIGURE 9. FLOW TO EACH FUEL CLUSTER IN MODEL CORE FOR OPERATION WITH TWO OPPOSED LOOPS 
Figure 10 is a map of the core showing flow distribution with two adjaceni luops in operation. Kegion 4 data were not rerun under this condition, and are not included on the data plot. In Cluster 32, flow was 3.7 per cent below the average flow for Region 3, and the usual high values for Clusters 103 and 126 were observed. All other points fell within 3 per cent of the average flow for each region. It will be noted that, in other tests, Cluster 32 passed less flow than others in Region 3, probably as the result of a low inlet-orifice coefficient. In Figure 10, the flow through Cluster 32 was 2.0 per cent lower than in the three-loop and four-loop tests.

From the data presented in Figures $7,8,9$, and 10 , it may be concluded that the influence of the number and orientation of loops in operation was small. Under all test conditions flow through each cluster was within three per cent of the average flow for clusters in the region in which it was located. If present errors resulting from differences in resistance of nominally similar orifices in simulated clusters could be eliminated by calibration of each cluster with both orifices in place, it is expected that changes in distribution found with changes in the number of loops in operation would be smaller than three per cent. Additional tests following such calibrations are planned.

Differences in flow through clusters within a region, and the relation of this variation with inlet conditions, can be shown graphically by plotting flow through each cluster against its location in the region, with locations of inlets marked. Such data plots have been prepared for the tests described above.

Figures 11, 12, 13, 14, and 15 show variations of flow which occur with four-loop operation.

Figures 16, 17, 18, 19 , and 20 show variations of flow which occur with three-loop operation.

Figures $21,22,23,24$, and 25 show variations of flow which occur with two opposite loops in operation. It will be noted that the two loops used for Region 4, Figure 24, are not the two used for other regions.

Figures 26, 27, 28, and 29 show variations in flow which occur with two adjacent loops in operation. No data for Region 4 were obtained for this configuration. 




$x 4747-8$

FIGURE 10. FLOW TO EACH FUEL CLUSTER IN MODEL CORE FOR OPERA TION WITH TWO ADJACENT LOOPS

Expressed as percentage of average flow for region. 


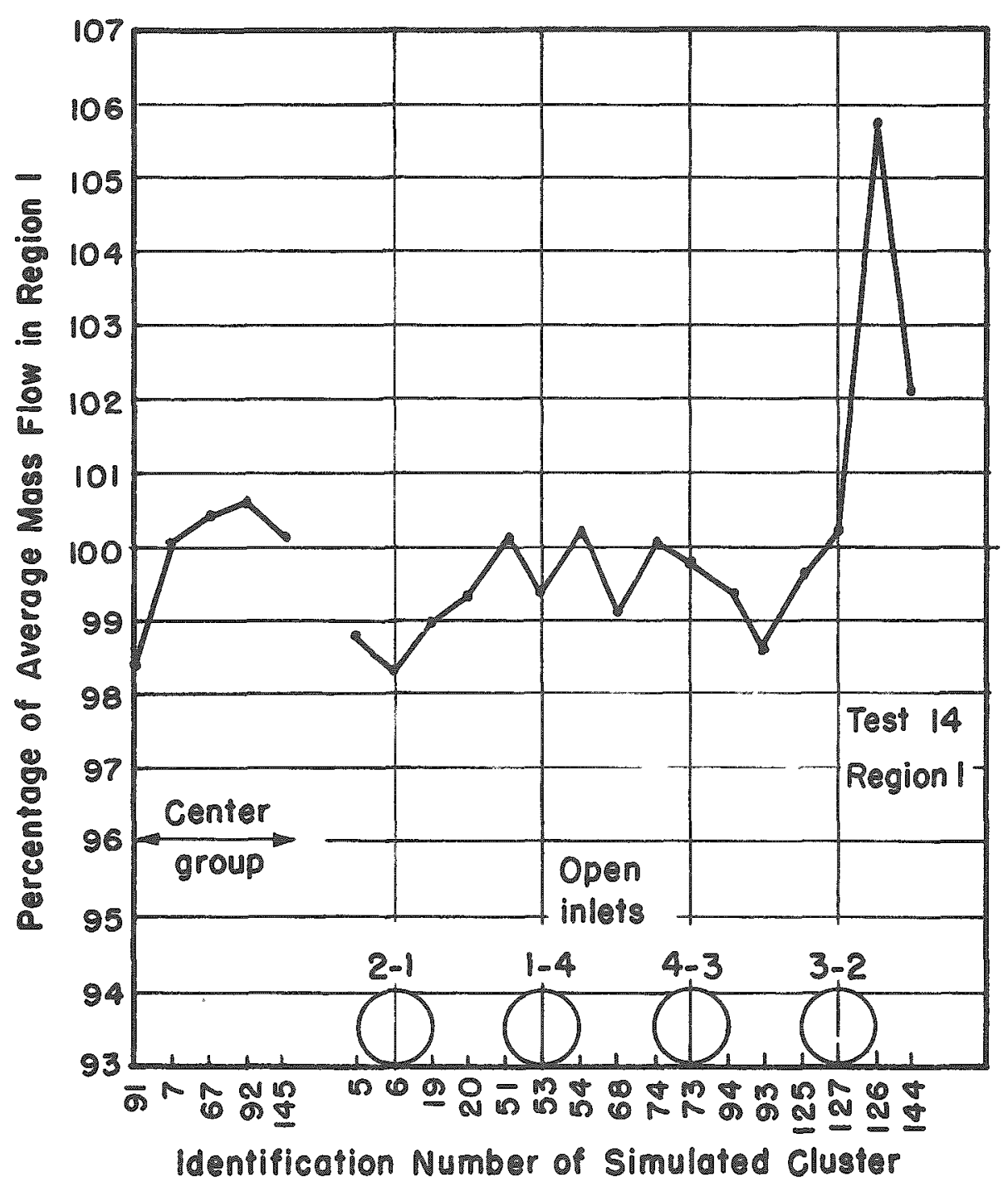

FIGURE 11. FLOW THROUGH CORE FUEL CLUSTERS IN TEST 14, REGION 1, 4-LOOP OPERATION 


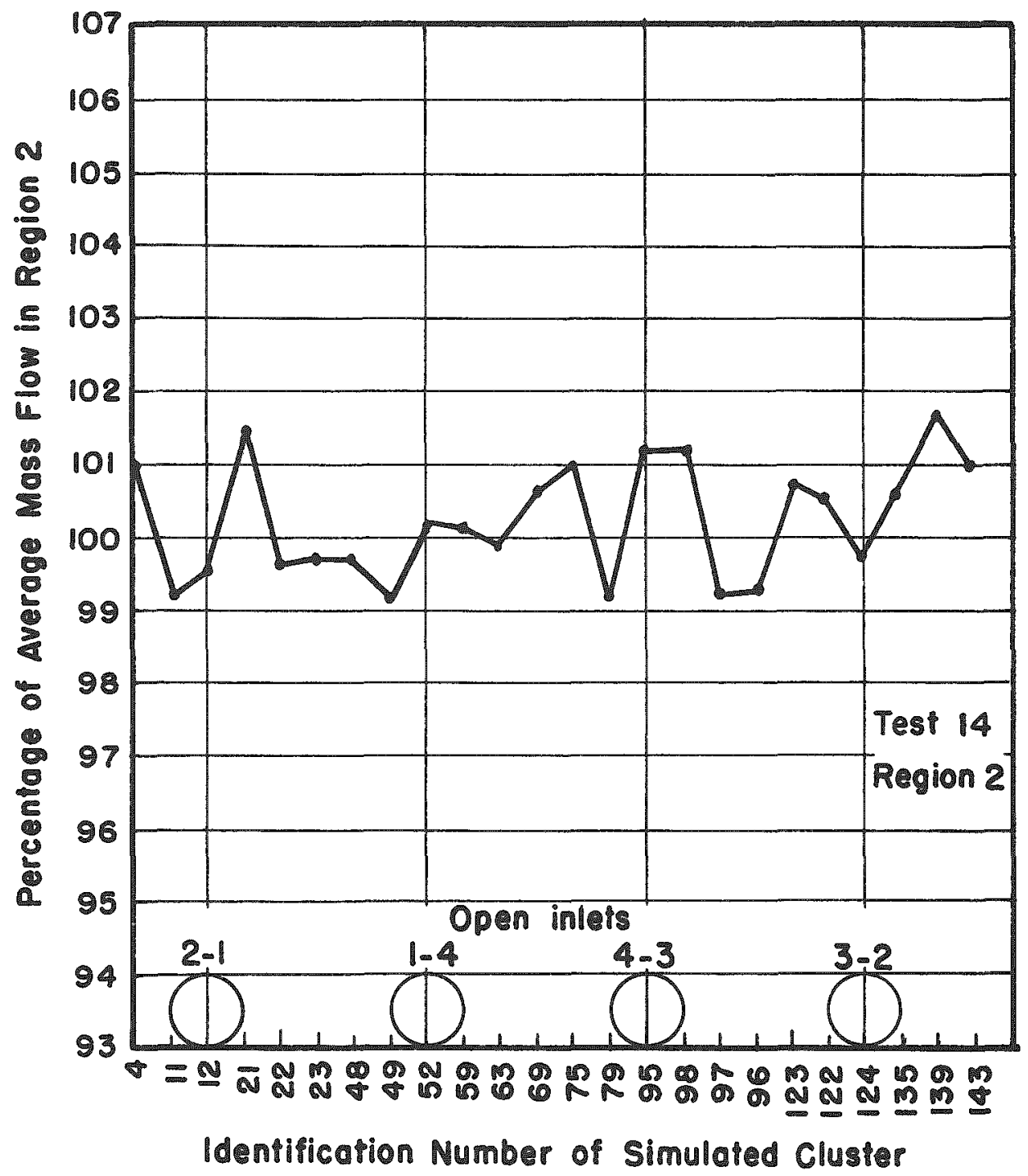

FIGURE 12. FLOW THROUGH CORE FUEL CLUSTERS IN TEST 14, REGION 2, 4-LOOP OPERATION 


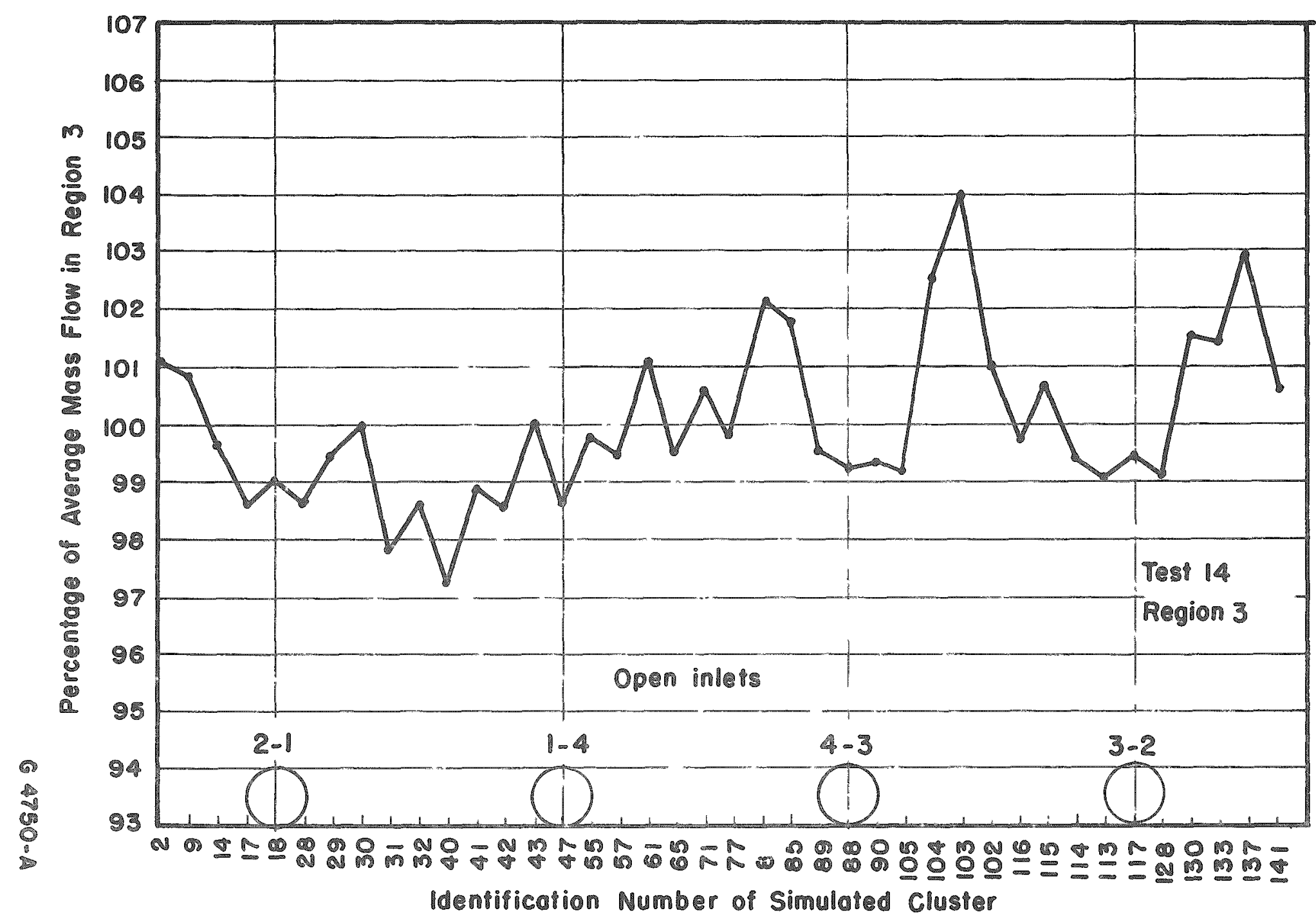

FIGURE 13. FLOW THROUGH CORE FUEL CLUSTERS IN TEST 14, REGION 3, 4-LOOP OPERATION 


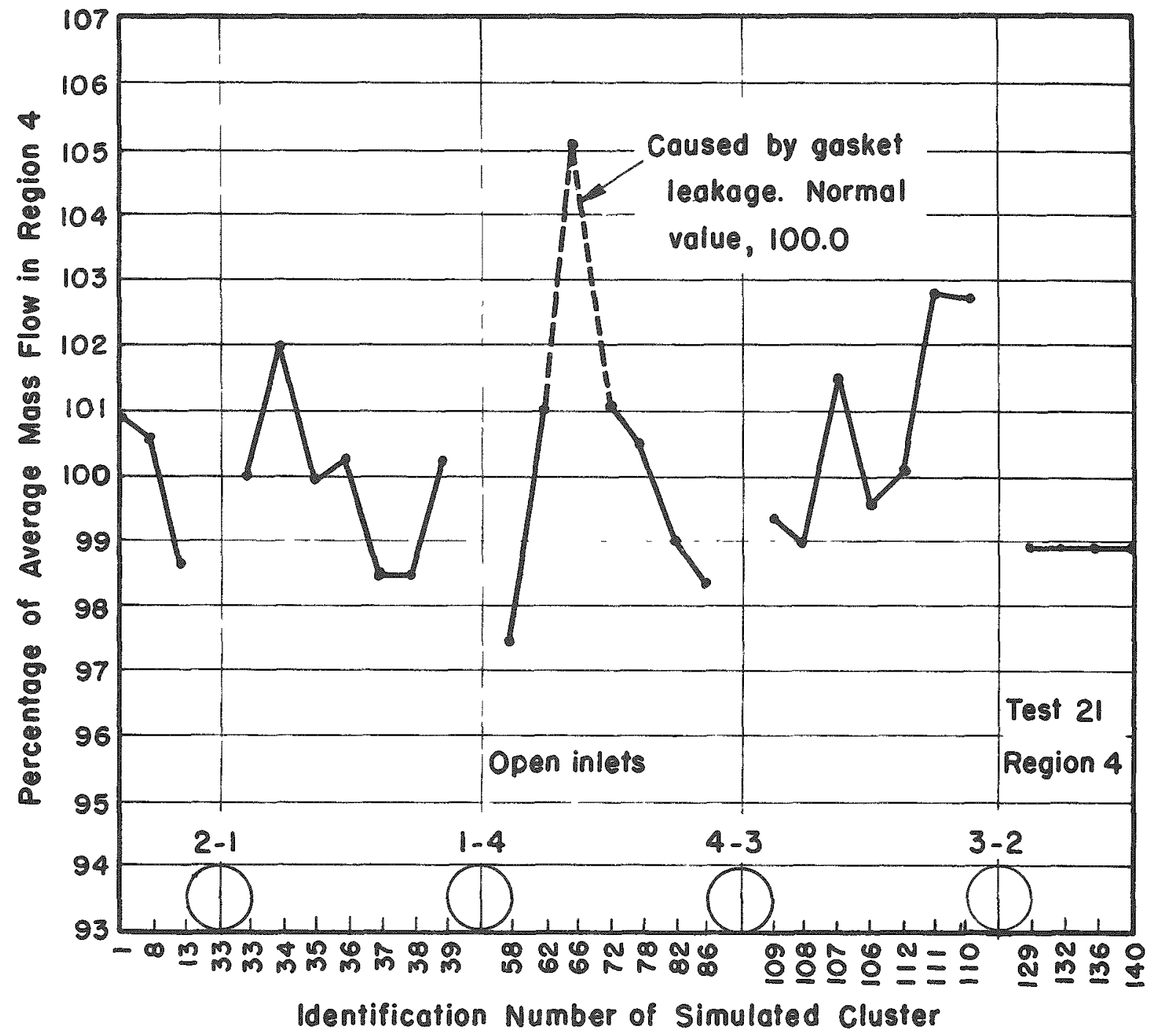

FIGURE 14. FLOW THROUGH CORE FUEL CLUSTERS IN TEST 21, REGION 4, 4-LOOP OPERATION 


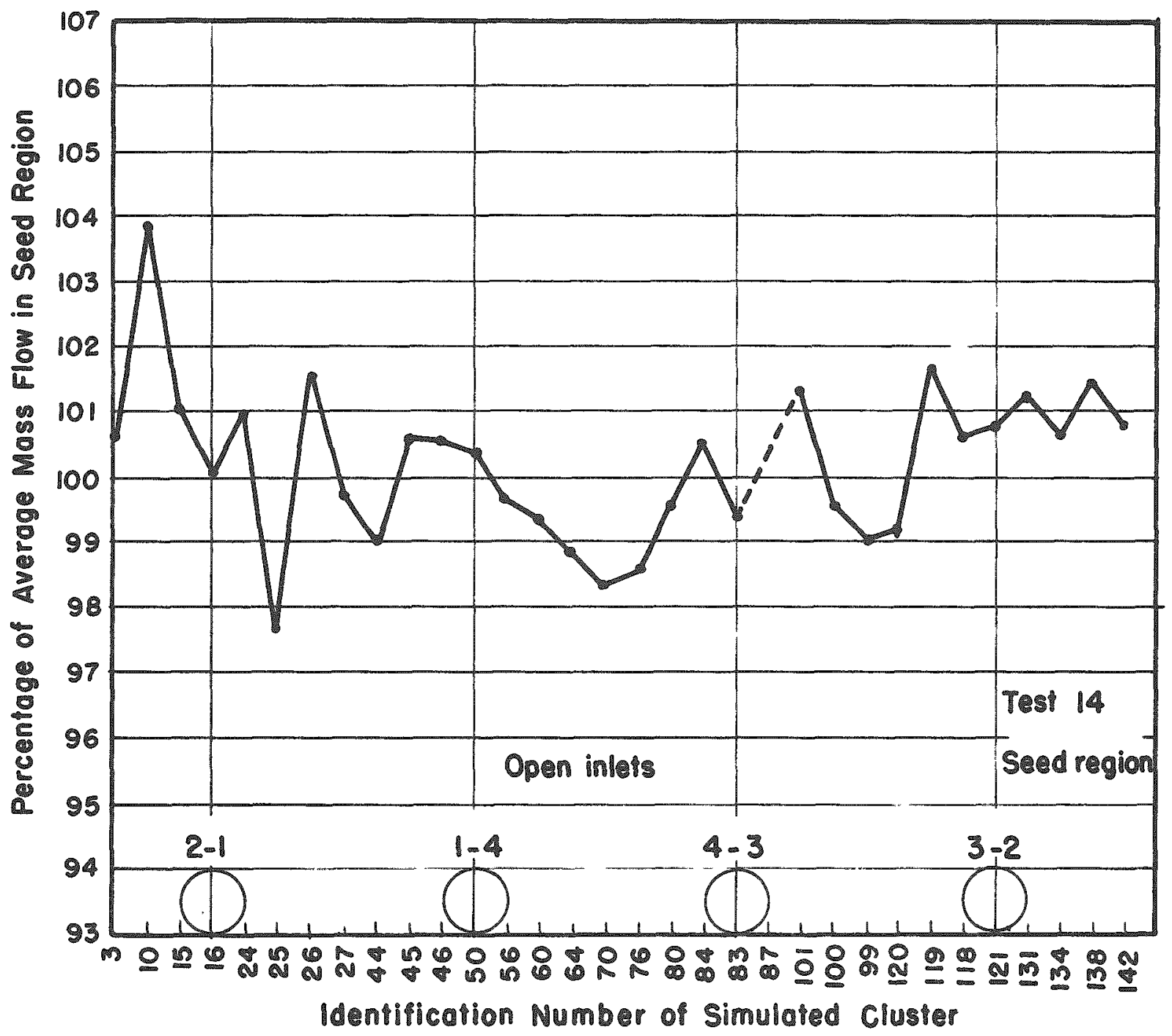

FIGURE 15. FLOW THROUGH CORE FUEL CLUSTERS IN TEST 14, SEED REGION, 4 LOOP OPERATION 


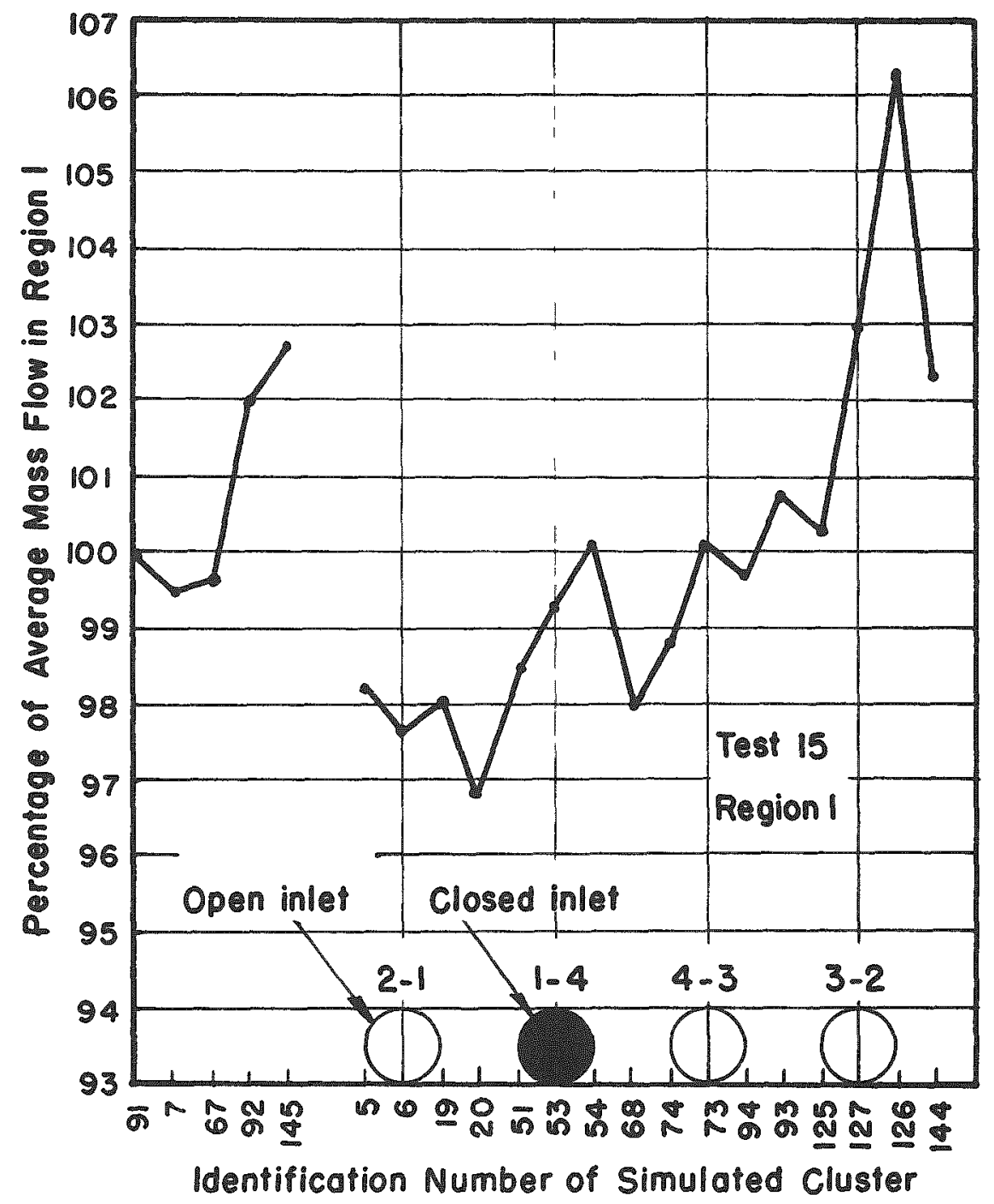

FIGURE 16. FLOW THROUGH CORE FUEL CLUSTERS IN TEST 15, REGION 1, 3-LOOP OPERATION

G 4753-A 


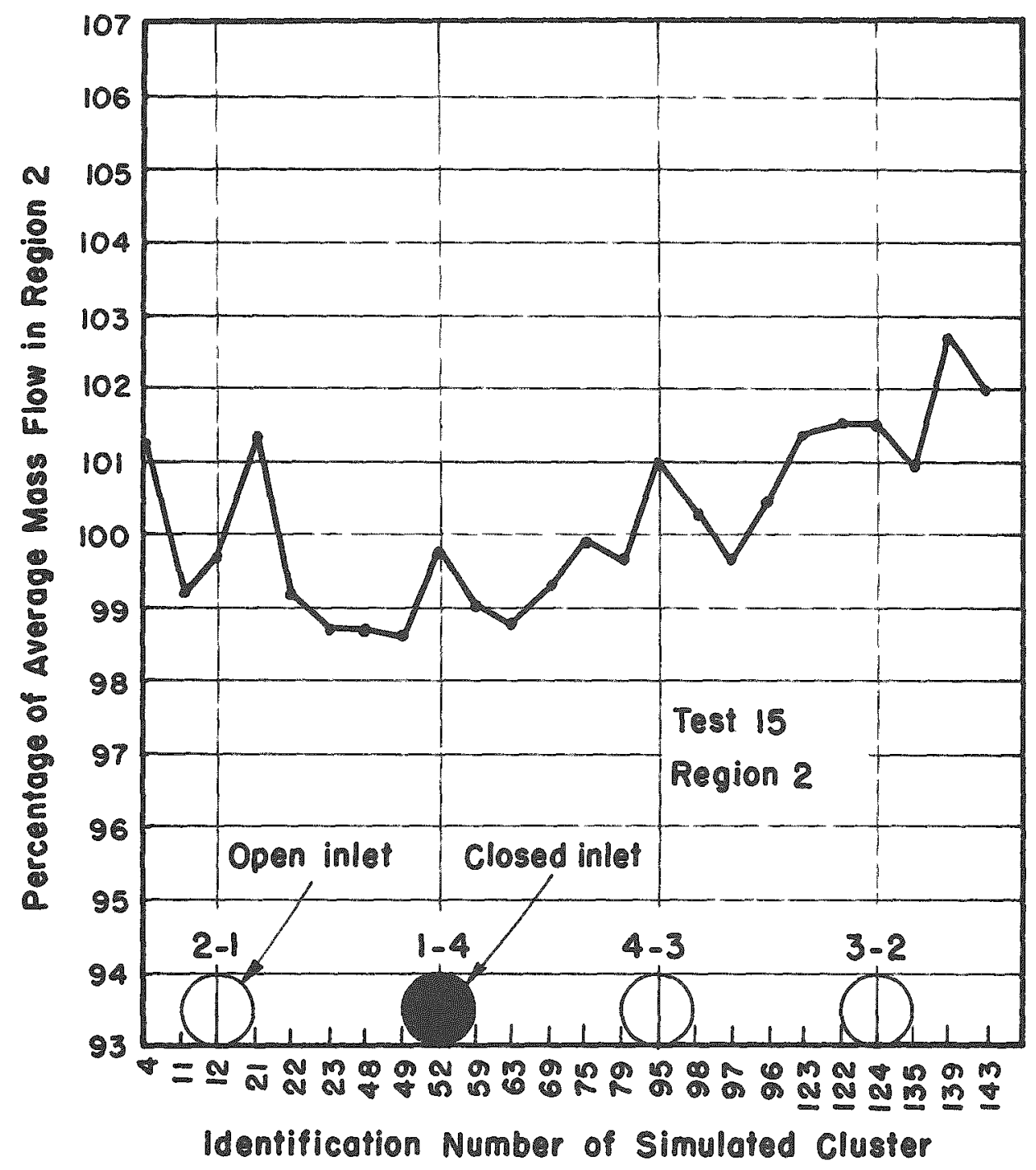

FIGURE 17. FLOW THROUGH CORE FUEL CLUSTERS IN TEST 15, REGION 2,3-LOOP OPERATION

$64754-A$ 
$\because ;$

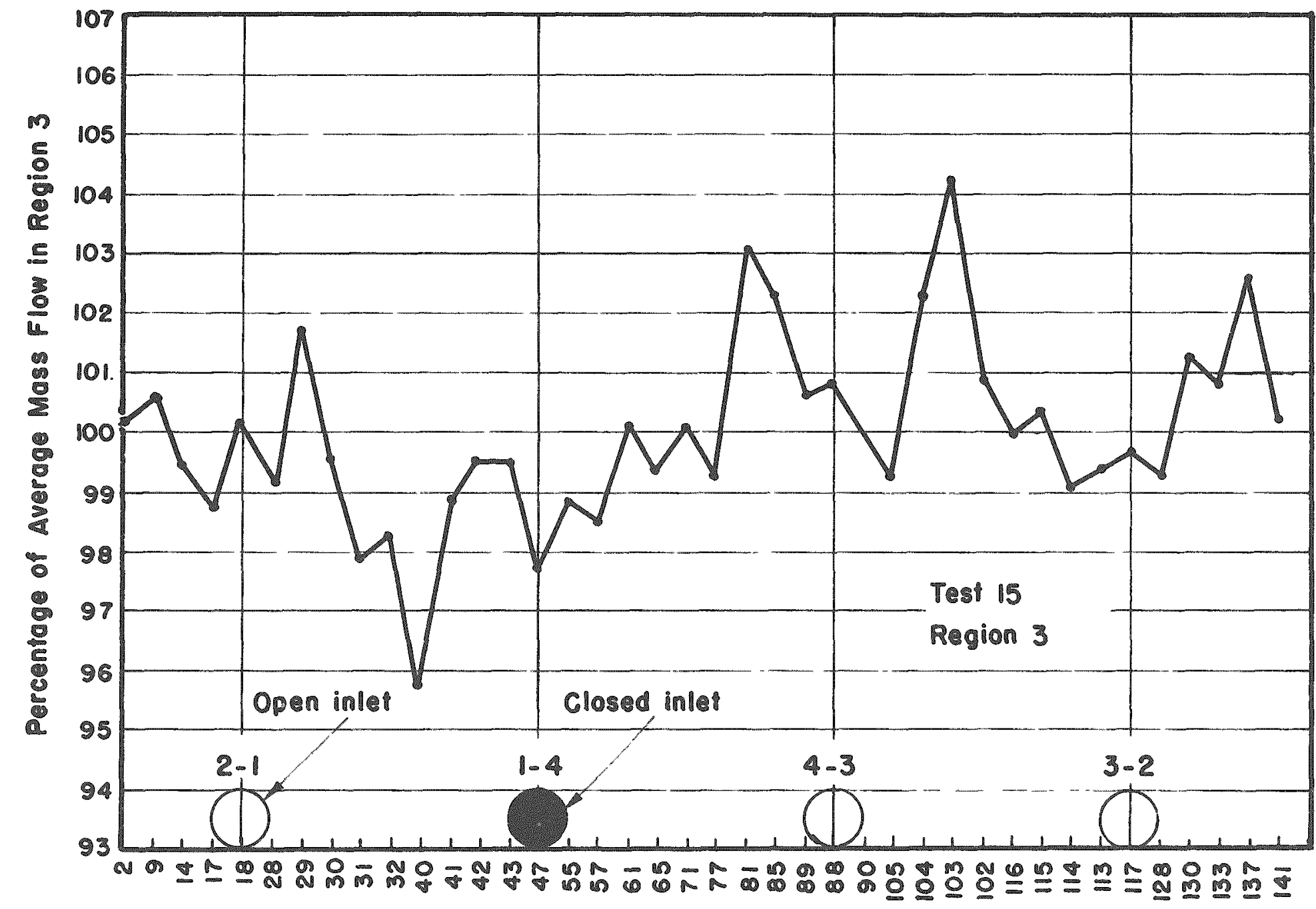

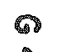
Identification Number of Simulated Clustor

FIGURE 18. FLOW THROUGH CORE FUEL CLUSTERS IN TEST 15, REGION 3 , 3-LOOP OPERATION 


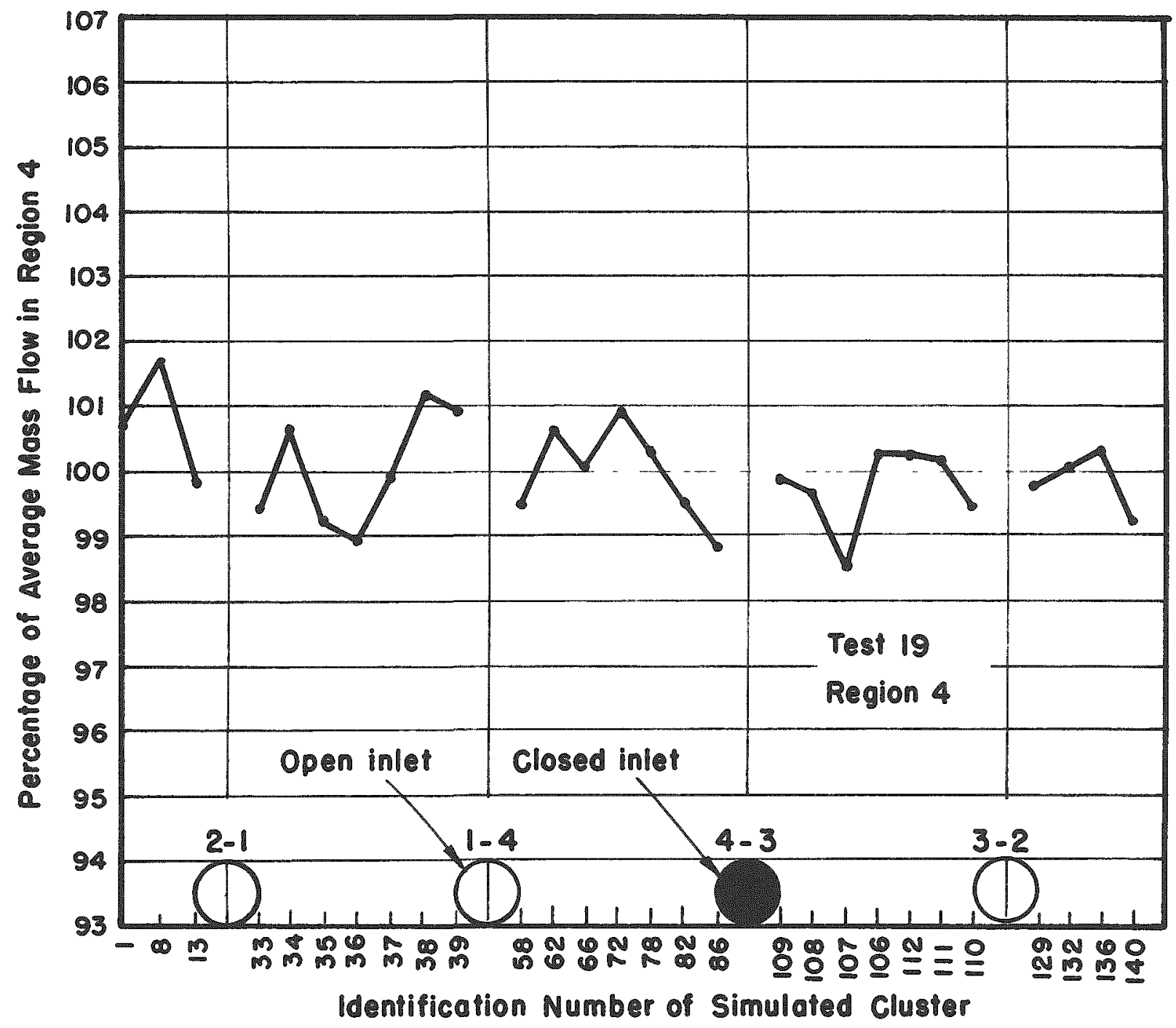

FIGURE 19. FLOW THROUGH CORE FUEL CLUSTERS IN TEST 19, REGION 4,3-LOOP OPERATION 


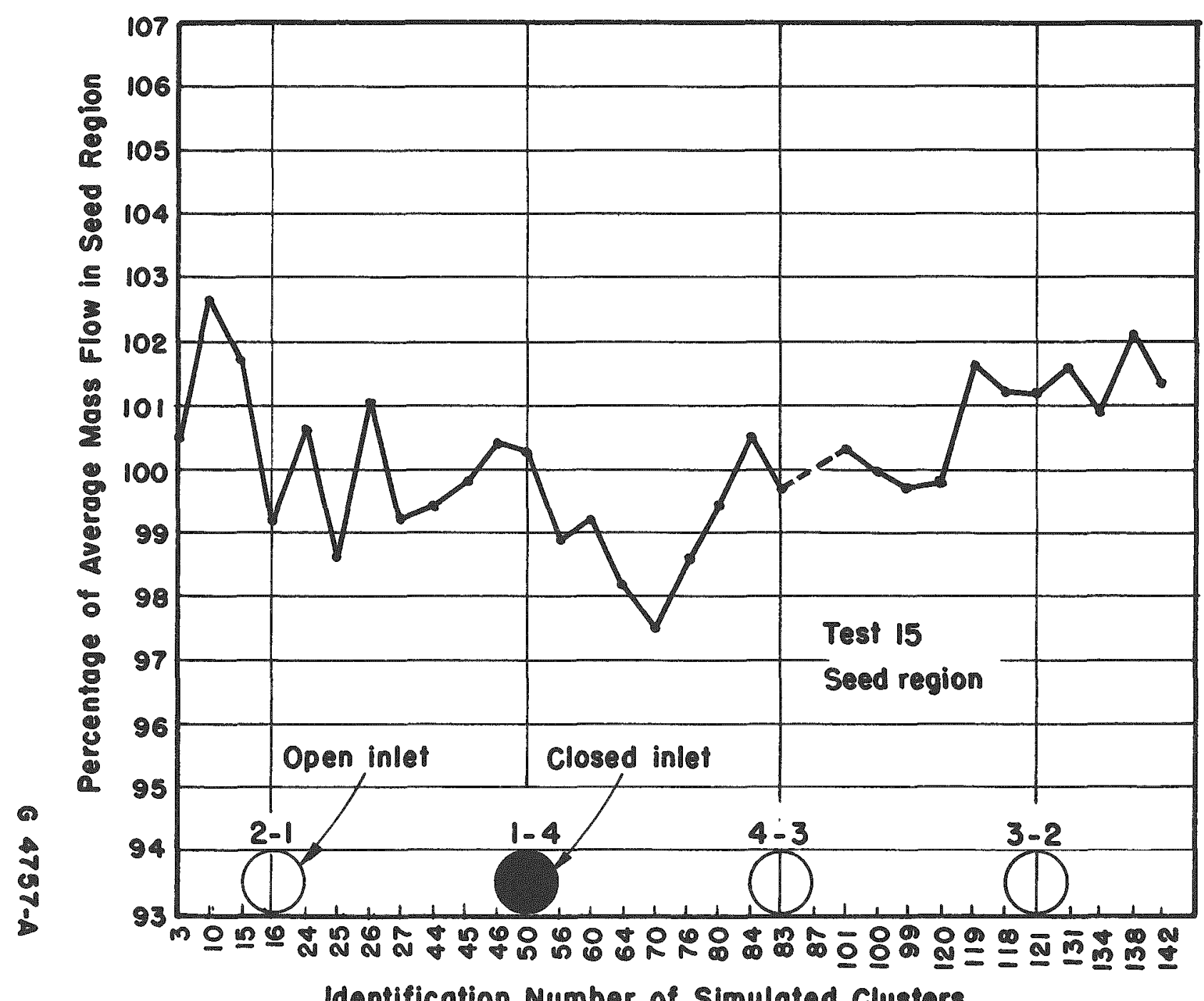

Identification Number of Simulated Clusters

FIGURE 20. FLOW THROUGH CORE FUEL CLUSTERS IN TEST 15, SEED REGION, 3-LOOP OPERATION 


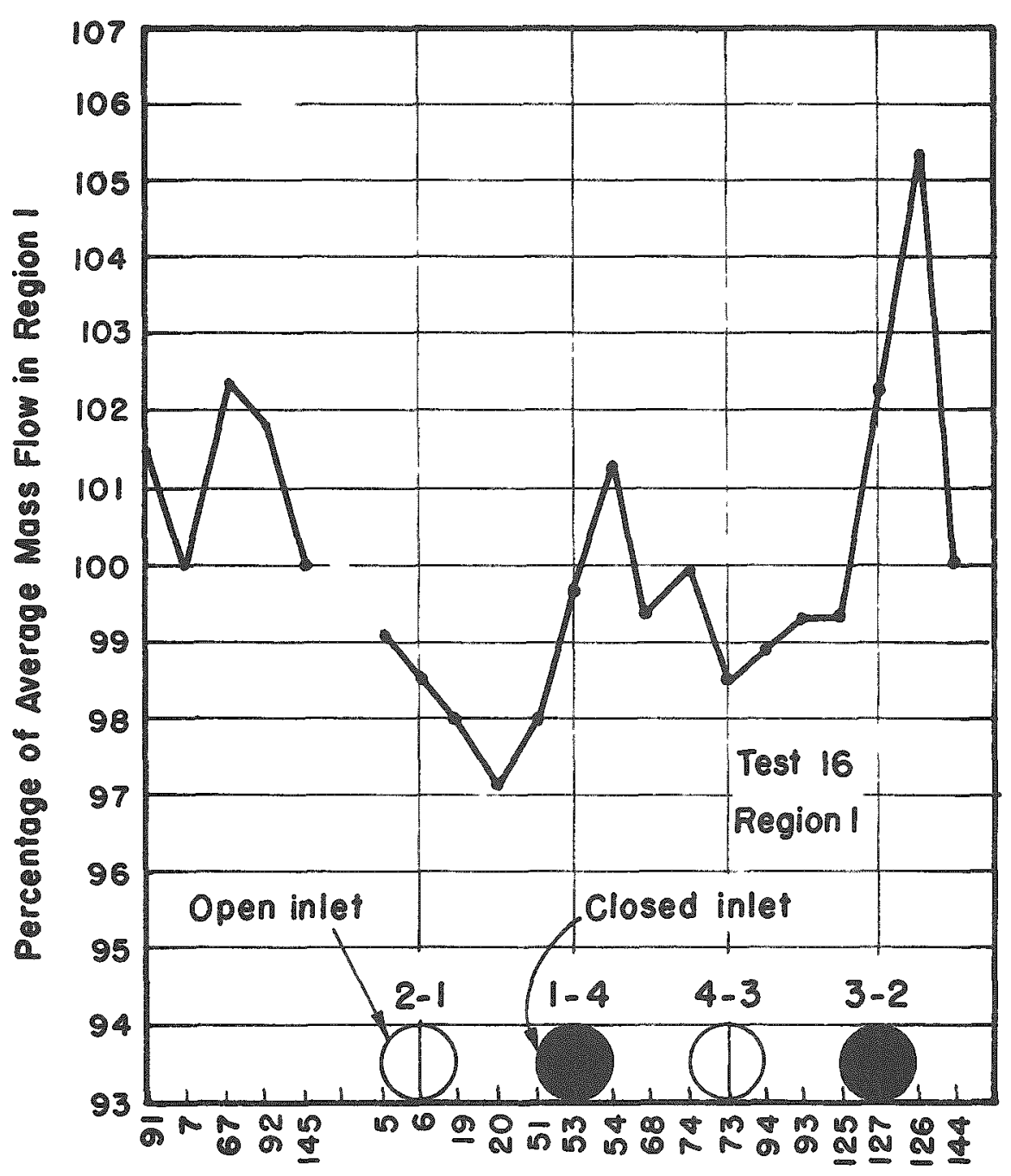

Idenfification Number, of Simulated Clasters

FIGURE 21. FLOW THROUGH CORE FUEL CLUSTERS IN TEST 16, REGION 1, 2-LOOP OPERATION 


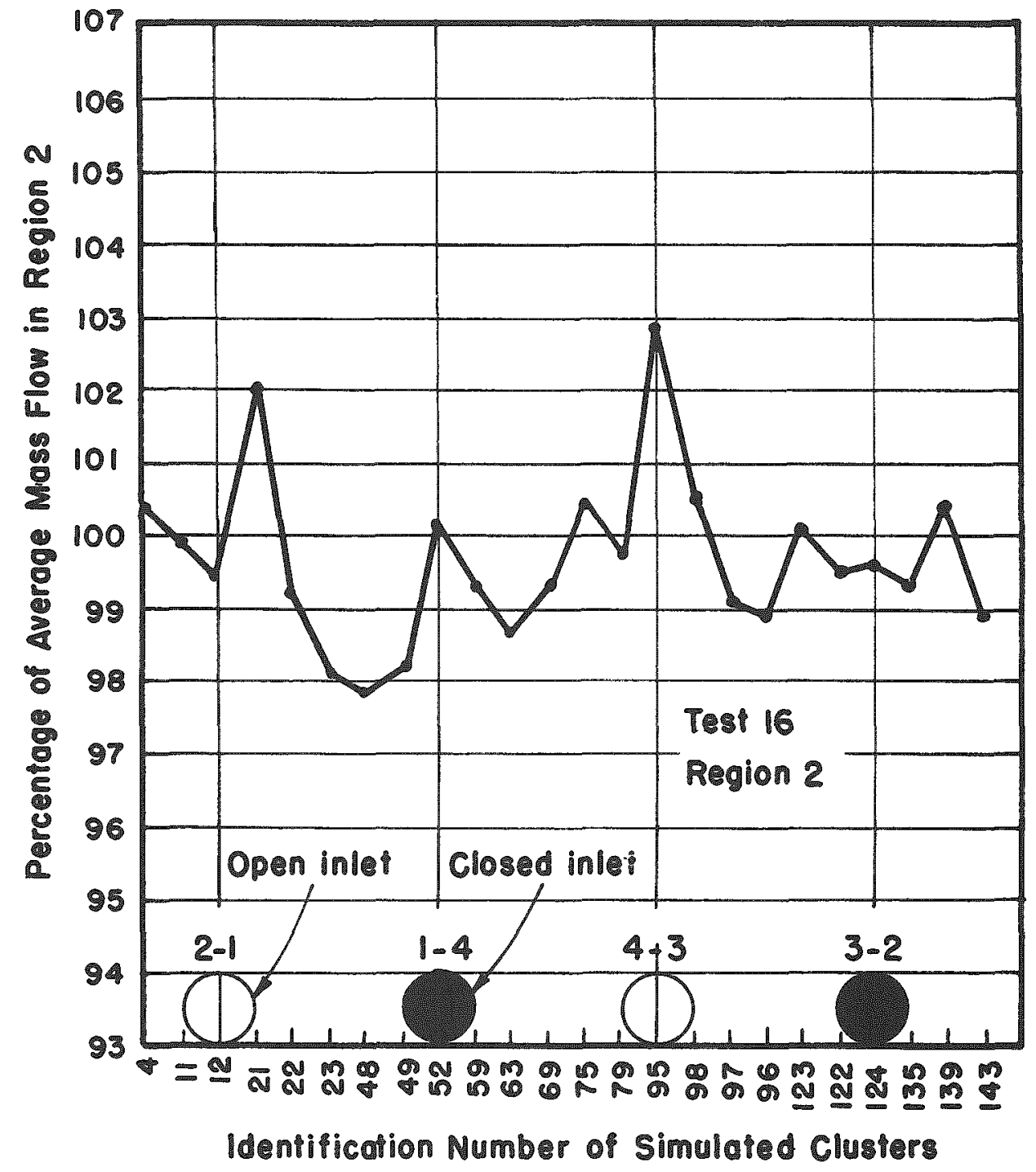

G 4759-A

FIGURE 22. FLOW THROUGH CORE FUEL CLUSTERS IN TEST 16, REGION 2, 2-LOOP OPERATION 


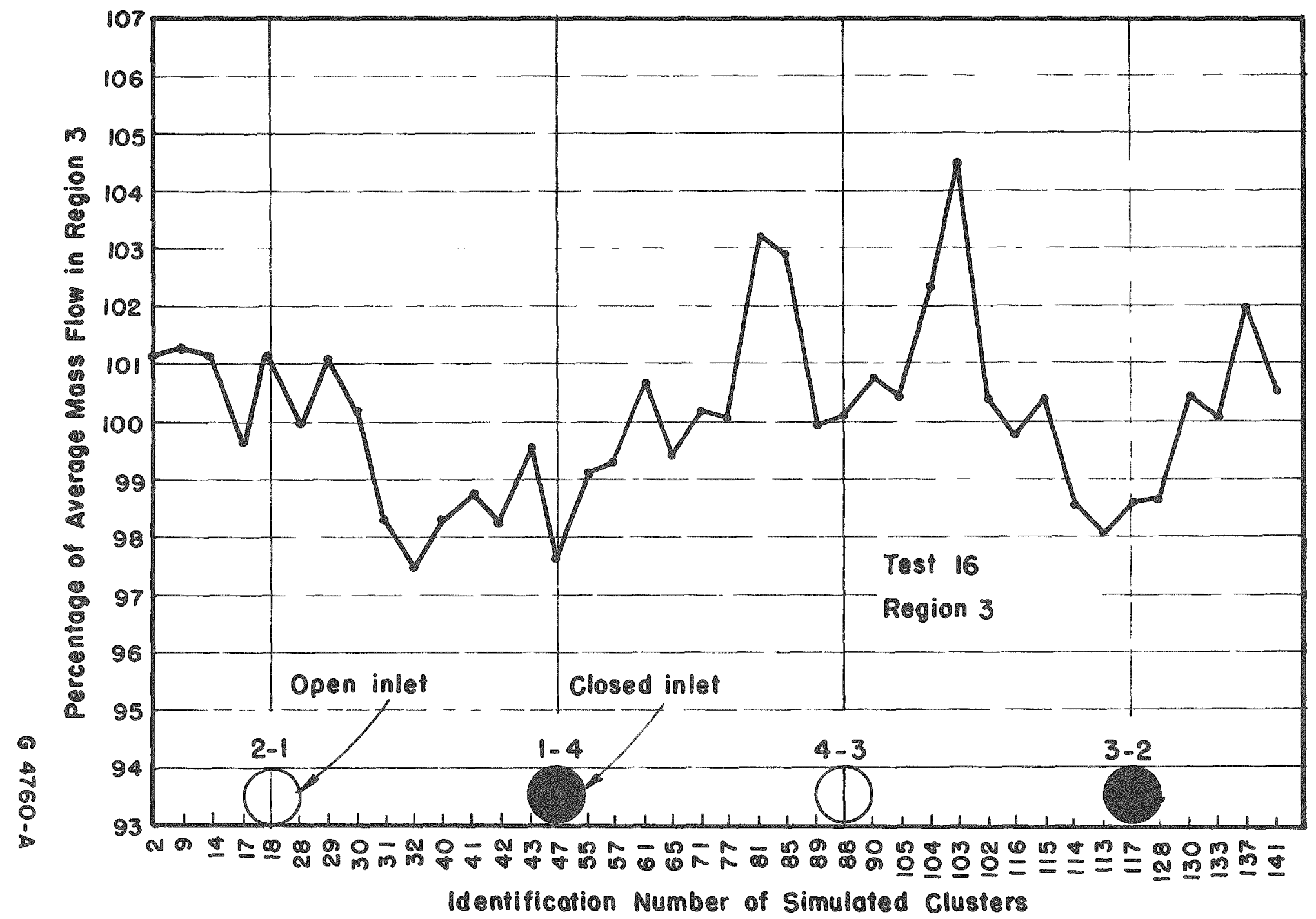

FIGURE 23. FLOW THROUGH CORE FUEL CLUSTERS IN TEST 16, REGION 3, 2-LOOP OPERATION 


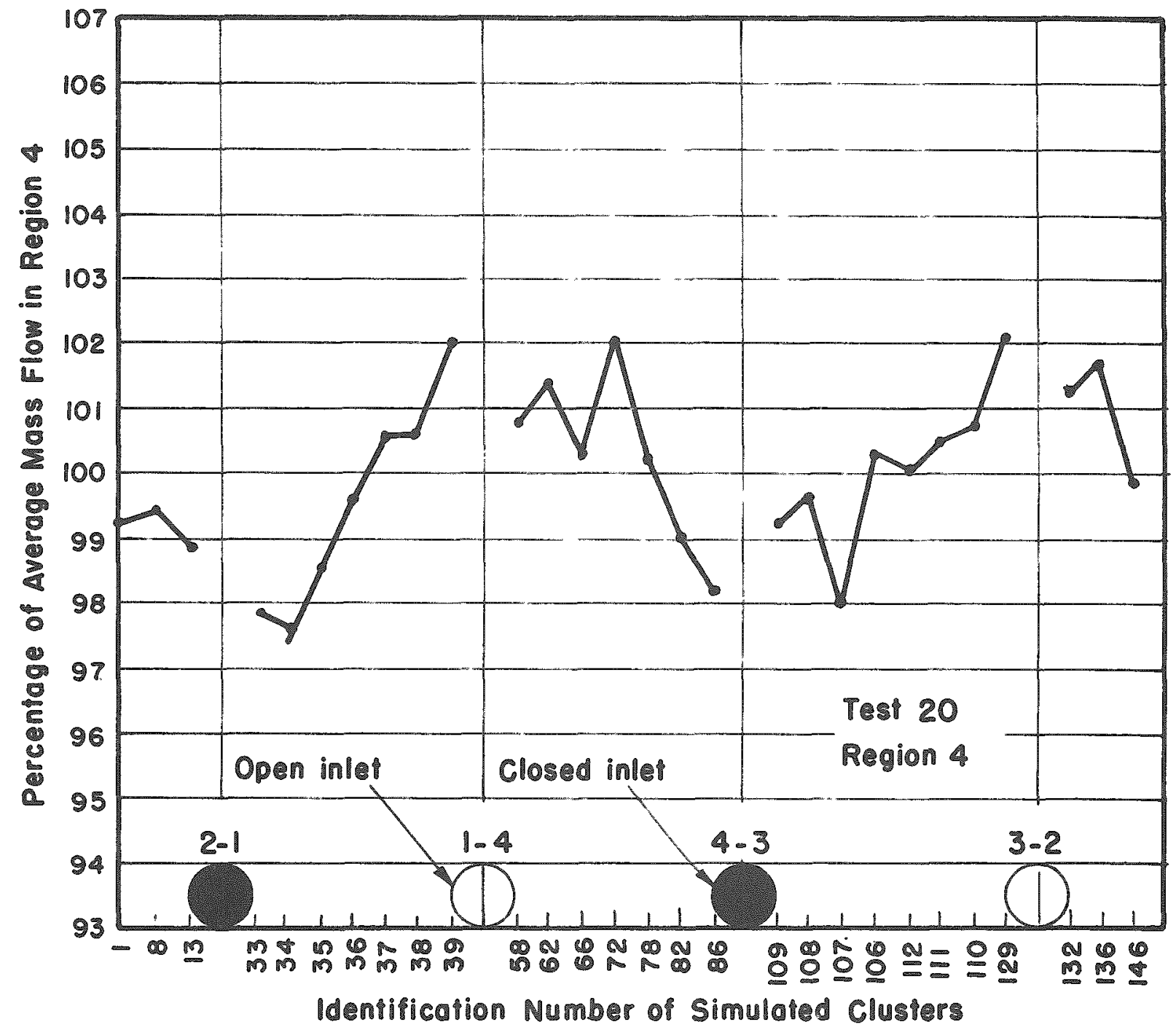

FIGURE 24. FLOW THROUGH CORE FUEL CLUSTERS IN TEST 20, REGION 4, 2-LOOP OPERATION 


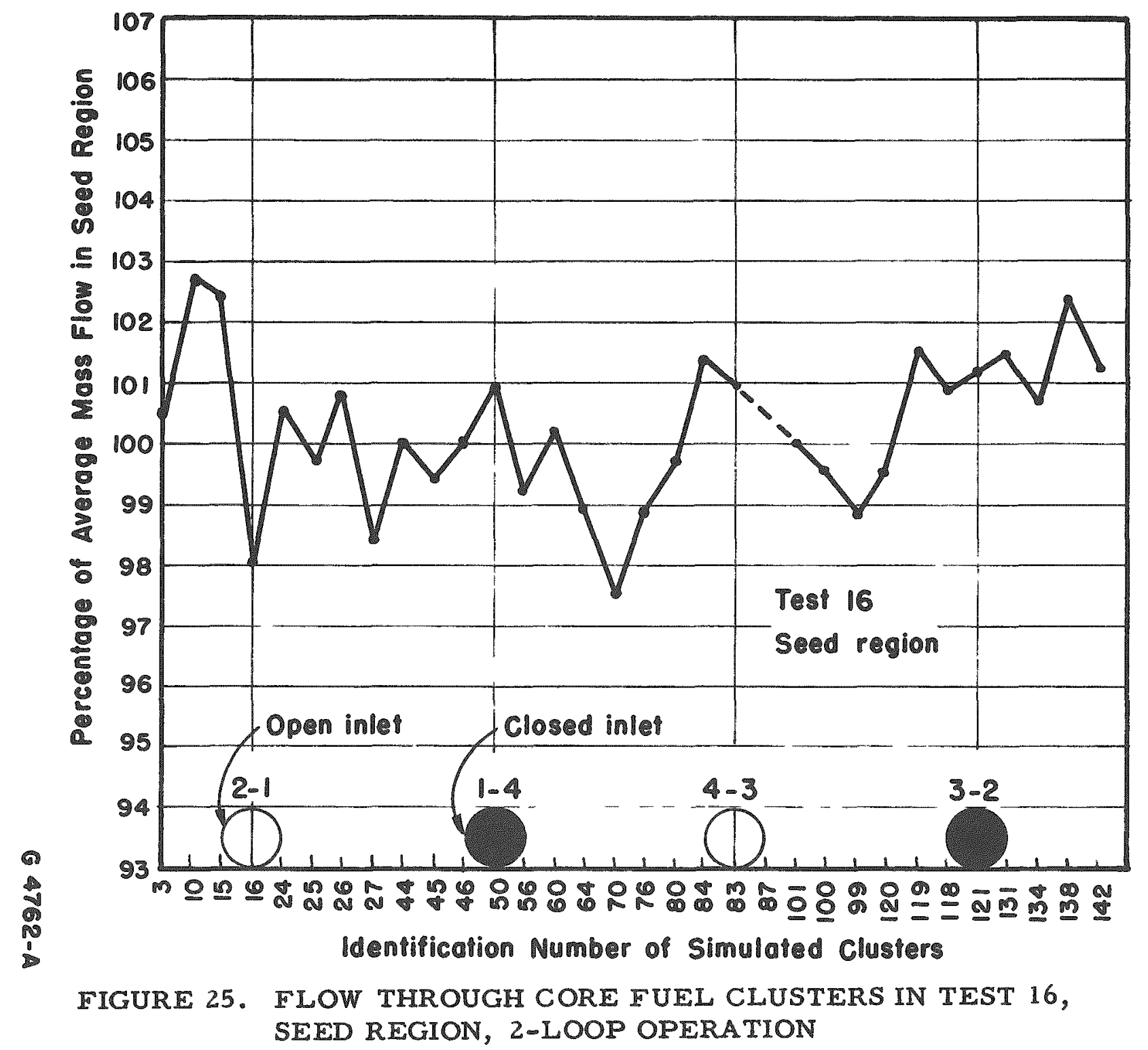




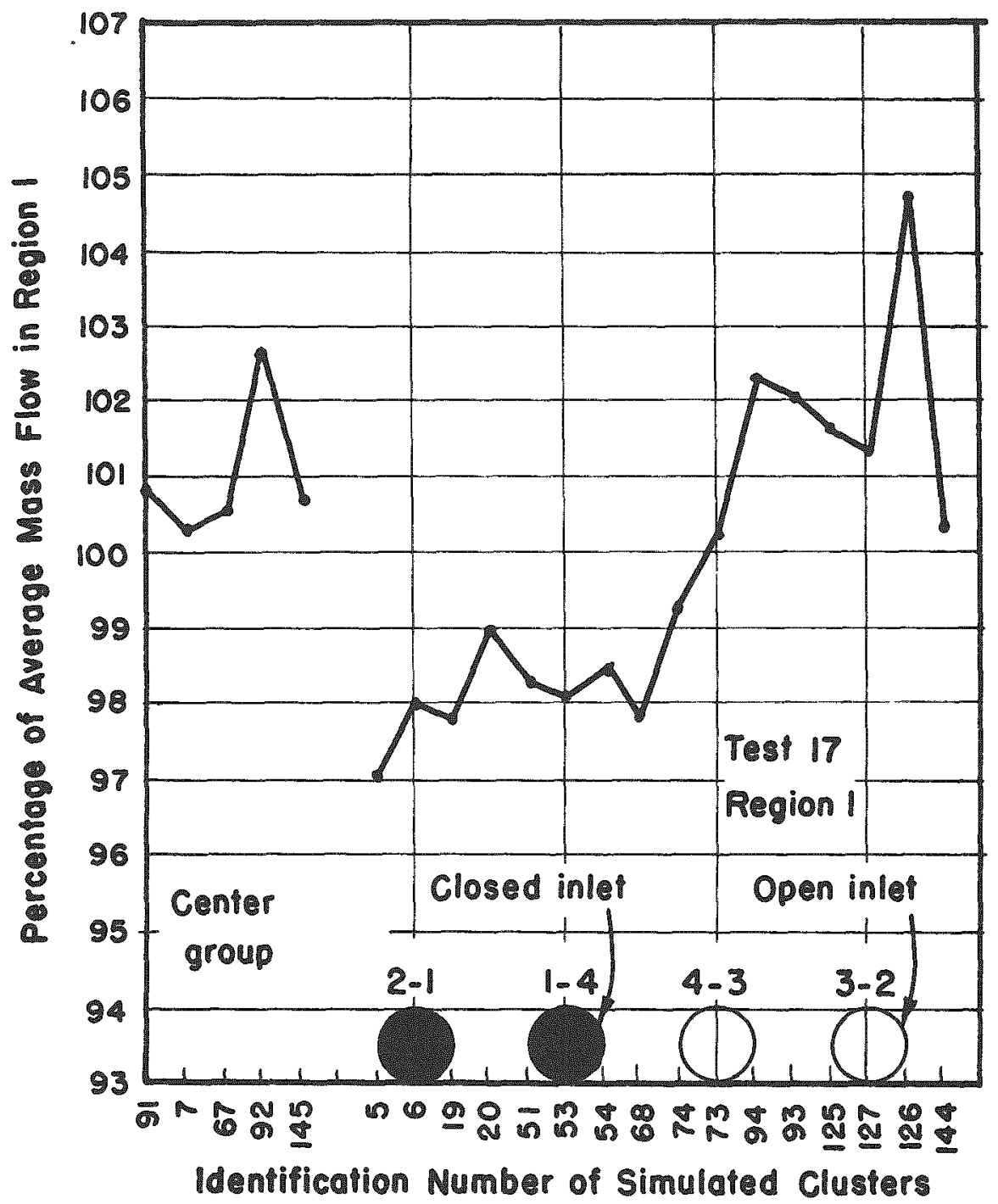

G $4763-A$

FIGURE 26. FLOW THROUGH CORE FUEL CLUSTERS IN TEST 17, REGION 1, 2-LOOP OPERATION 


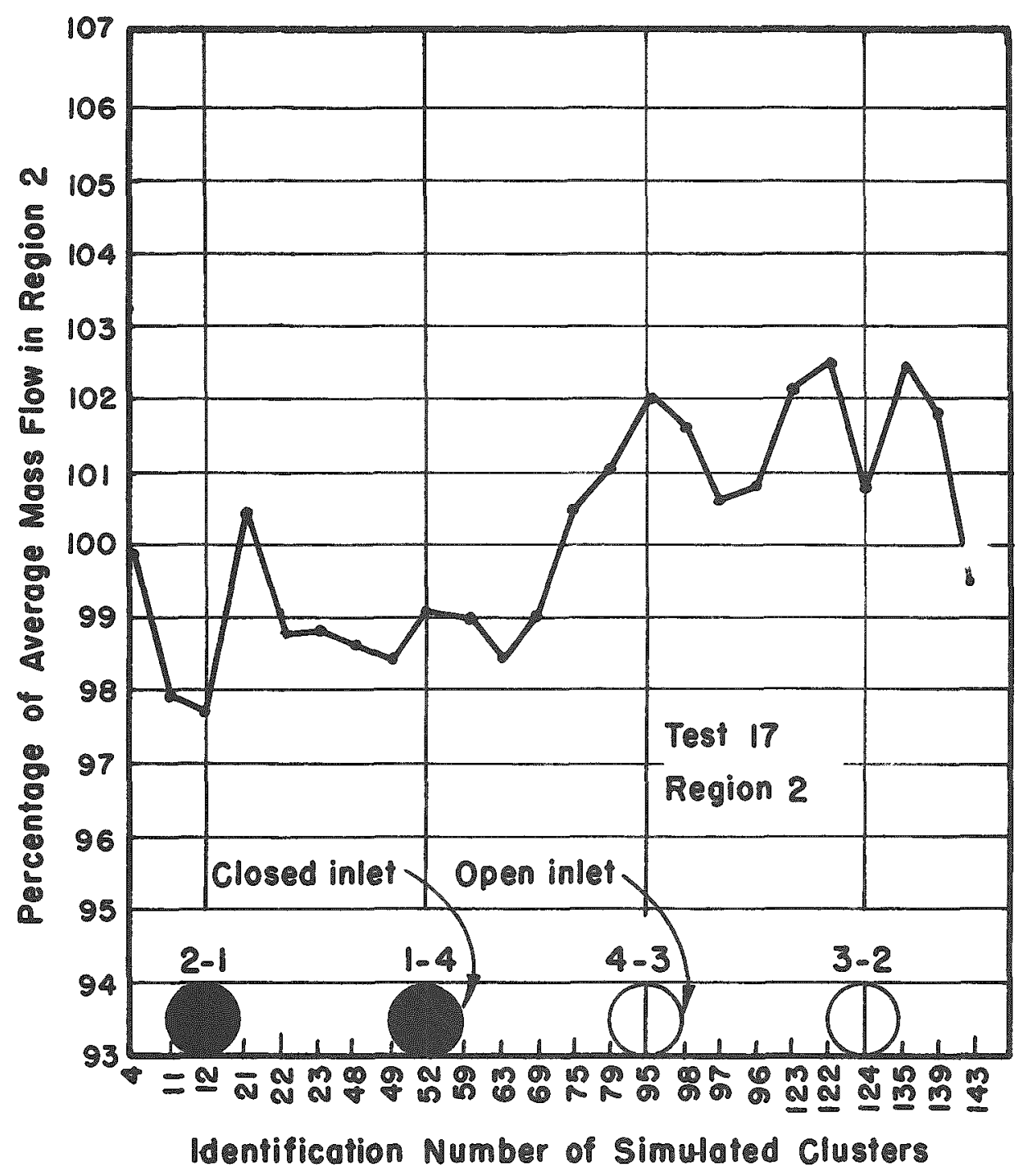

$64764-A$

FIGURE 27. FLOW THROUGH CORE FUEL CLUSTERS IN TEST 17, REGION 2, 2-LOOP OPERATION 


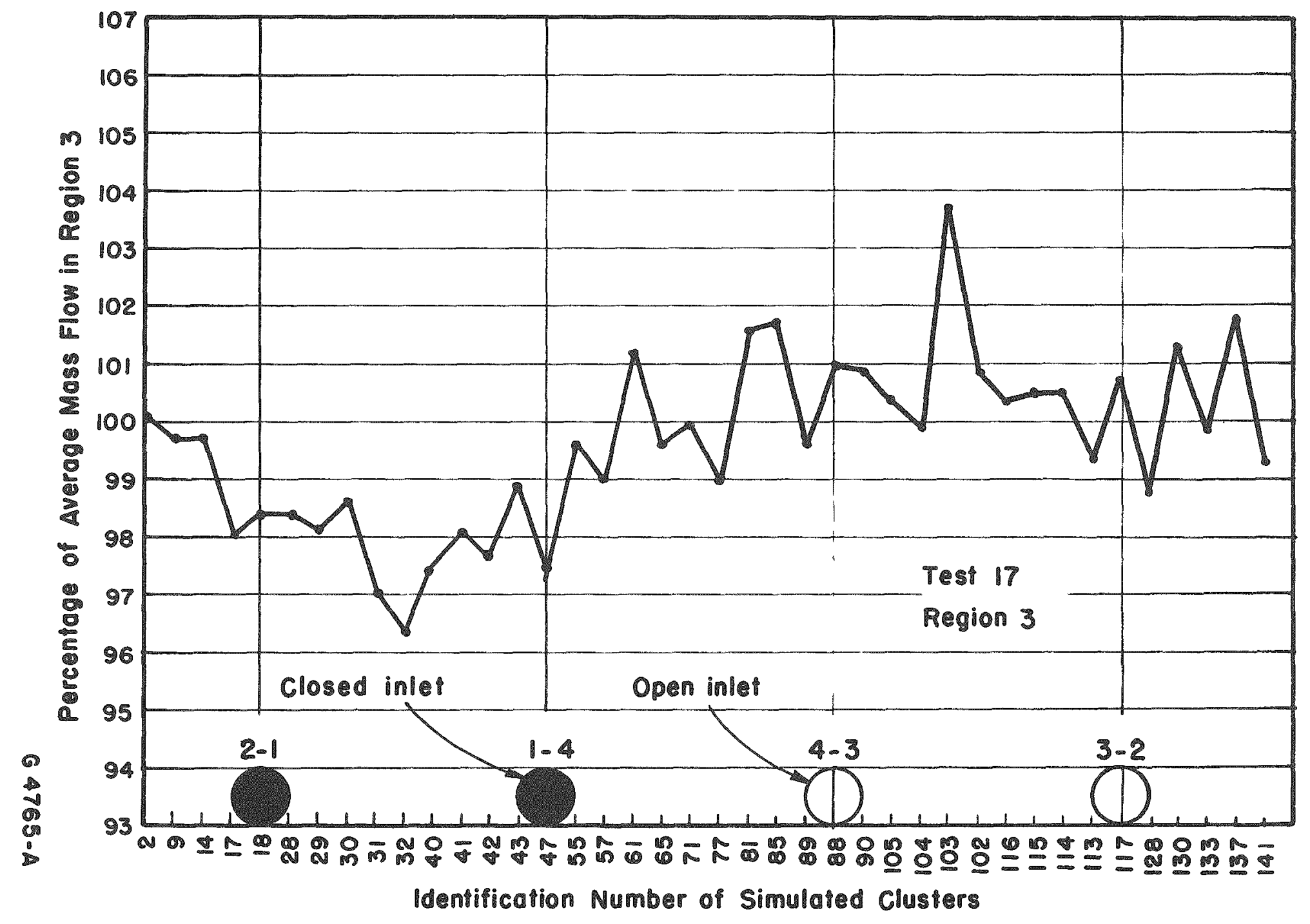

FIGURE 28. FLOW THROUGH CORE FUEL CLUSTERS IN TEST 17, REGION 3, 2-LOOP OPERATION 


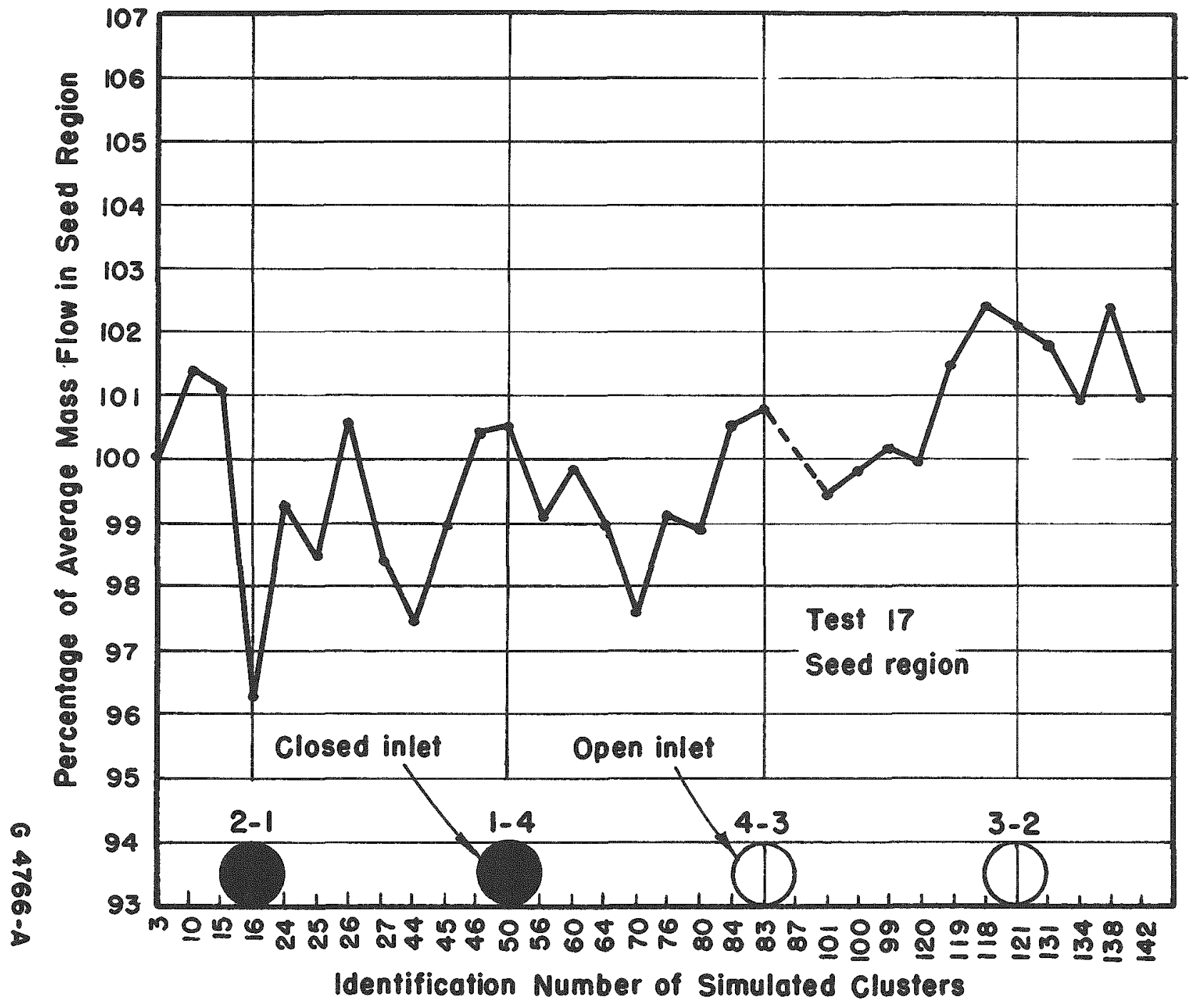

FIGURE 29. FLOW THROUGH CORE FUEL CLUSTERS IN TEST 17, SEED REGION, 2-LOOP OPERATION 


\section{RECOMMENDATIONS}

Additional Studies in the Quarter-Scale Model

It is recommended that the studies of core flow distribution described in this report be supplemented by an additional set of tests following a complete calibration with all core orifices in place. For such a calibration, each simulated fuel cluster would be calibrated with both the flow-measuring orifice and the restricting orifice in place, using the same pressure differential for air flow through each simulated cluster. Such a calibration should eliminate much of the variation in distribution of flow within regions shown in this report, and more clearly show the effects of the number and orientation of loops. Such a calibration and tests are scheduled for November, 1956.

\section{Future Model Design}

The use of orifices within the core structure appears to be a practical and accurate means of measuring flow through individual simulated fuel clusters. However, it appears that even with careful manufacturing and close tolerances, coefficients of nominally identical orifices will vary. Thus, provision should be made for calibration of such orifices in place early in the test program. If this is not possible because of core design, orifices should be calibrated in place in subassemblies as the model is being as sembled. With the small orifices used in the PWR model, orifice coefficients were found to vary by as much as 2.5 per cent from the average coefficient for all orifices of one size.

The use of sponge-rubber gaskets in areas where compressive forces are small is recommended to minimize leakage through gasketed joints. In the PWR model, replacement of firm-rubber gaskets with gaskets cut from 1/16-in. sponge rubber eliminated leakage.

\section{ACKNOWLEDGMENTS}

The work reported was performed by J. M. Allen, L. J. Flanigan, J. Huggins, Charles Pollock, and Richard Johnston, under the supervision of Herbert $R$. Hazard. The work was done under WAPD reference No, 73(14-452). Mr. Frank Grochowski, of the Westinghouse Atomic Power Division, coordinated the work for Westinghouse and contributed much to the over-all planning of the research. His assistance is appreciated. 


\section{APPENDIX}

CORRECTION FACTORS FOR MEASURING ORIFICES IN CORE OF QUARTER-SCALE FLOW MODEI OF THE PWR REACTOR 
CORRECTION FACTORS FOR MEASURING ORIFICES IN CORE OF QUARTER-SCALE FLOW MODEL OF THE PWR REACTOR

The core of the PWR flow model is divided into five regions, each with different flow requirements. The nominal sizes of the orifices in each re gion are identical, and the sizes of all orifices in the four blanket regions were selected to give a differential of $48 \mathrm{in}$. water with a model flow of 5.33 lb per sec. At this flow, the seed-region orifices were selected to give a differential of 103.5 in. water.

Orifices in each region were calibrated by passing the same measured flow of air through each orifice, and reducing the pressure differentials observed on the manometer panel to correction factors, which could be multiplied by square roots of the observed differentials for each core test. The differentials observed during calibration were reduced to square roots and averaged. This average was then divided by the square root of each differential, giving correction factors which are shown in Table A-1. The correction factor for each cluster is multiplied by the square root of the observed pressure differential for that cluster in each test, to correct for variations in orifice geometry.

Variations in the flow resistance of the orifices result in two conditions: a variation of flow through the orifice, and an error in measuring the flow through the orifice. The correction factors in Table A-1 correct the exror in measurement of flow, but have no bearing on the changes in actual flow which may result from differences in orifice flow resistance. 


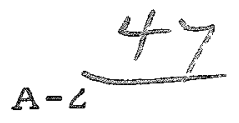

TABLE A-1. CORRECTION FACTORS FOR FLOW-MEASURING ORIFICES IN THE CORE OF THE QUARTER=SCALE FLOW MODEL, OF PWR REACTOR

\begin{tabular}{|c|c|c|c|c|c|c|c|c|c|}
\hline \multicolumn{2}{|c|}{ Region 1} & \multicolumn{2}{|c|}{ Region 2} & \multicolumn{2}{|c|}{ Region 3} & \multicolumn{2}{|c|}{ Region 4} & \multicolumn{2}{|c|}{ Seed Region } \\
\hline & Correction & & Correction & & $\overline{\text { Correction }}$ & & Correction & & Correction \\
\hline Cluster & Factor & Cluster & Factor & Cluster & Factor & Cluster & Eactor & Cluster & Factor \\
\hline 91 & 0.996 & 4 & 0.985 & 2 & 0.994 & 1 & 1.016 & 3 & 1.003 \\
\hline 7 & 1.001 & 11 & 0.985 & 9 & 0.999 & 8 & 0.985 & 10 & 1.054 \\
\hline 67 & 1.009 & 12 & 1.055 & 14 & 0.994 & 13 & 0.991 & 15 & 0.995 \\
\hline 92 & 0.999 & 21 & 1.024 & 17 & 0.990 & 33 & 0.985 & 16 & 0.997 \\
\hline 145 & 0.986 & 22 & 0.980 & 18 & 0.999 & 34 & 1.034 & 24 & 1.058 \\
\hline 5 & 0.988 & 23 & 0.997 & 28 & 0.994 & 35 & 1.002 & 25 & 0.980 \\
\hline 6 & 0.993 & 48 & 0.995 & 29 & 0.983 & 36 & 0.979 & 26 & 1.077 \\
\hline 19 & 0.986 & 49 & 0.985 & 30 & 0.996 & 37 & 0.985 & 27 & 1.009 \\
\hline 20 & 0.988 & 52 & 0.992 & 31 & 1.004 & 38 & 0.982 & 44 & 0.965 \\
\hline 51 & 1.001 & 59 & 1.013 & 32 & 1.022 & 39 & 0.995 & 45 & 1.018 \\
\hline 53 & 0.999 & 63 & 1.003 & 40 & 1.017 & 58 & 1.026 & 46 & 1.032 \\
\hline 54 & 1.025 & 69 & 1.018 & 41 & 1.004 & 62 & 0.992 & 50 & 1.001 \\
\hline 68 & 1.006 & 75 & 1.016 & 42 & 0.994 & 66 & 0.985 & 56 & 0.996 \\
\hline 74 & 1.022 & 79 & 1.013 & 43 & 1.012 & 72 & 0.992 & 60 & 0.984 \\
\hline 73 & 1.001 & 95 & 0.992 & 47 & 0.997 & 78 & 0.982 & 64 & 0.989 \\
\hline 94 & 1.006 & 98 & 0.987 & 55 & 1.002 & 82 & 0.982 & 70 & 0.999 \\
\hline 93 & 0.999 & 97 & 0.985 & 57 & 1.017 & 86 & 1.023 & 76 & 0.950 \\
\hline 125 & 0.999 & 96 & 0.992 & 61 & 1.002 & 109 & 0.995 & 80 & 0.986 \\
\hline 127 & 1.006 & 123 & 1.032 & 65 & 1.002 & 108 & 1,012 & 84 & 0.986 \\
\hline 126 & 0.991 & 122 & 0.985 & 71 & 1. 009 & 107 & 0.995 & 83 & 0.988 \\
\hline \multirow[t]{20}{*}{144} & 1.006 & 124 & 0.978 & 77 & 0.999 & 106 & 0.998 & 87 & $\infty$ \\
\hline & & 135 & 1.005 & 81 & 0.994 & 112 & 1.037 & 101 & $1.04 y$ \\
\hline & & 139 & 0.990 & 85 & 0.997 & 111 & 0.995 & 100 & 0.990 \\
\hline & & 143 & 0.992 & 89 & 1.002 & 110 & 1.002 & 99 & 0.963 \\
\hline & & & & 88 & 0.999 & 129 & 1.002 & 120 & 0.963 \\
\hline & & & & 90 & 1.028 & 132 & 0.992 & 119 & 1.031 \\
\hline & & & & 105 & 0.973 & 136 & 1.002 & 118 & 0.990 \\
\hline & & & & 104 & 0.997 & 1.40 & 1.052 & 121 & 0.992 \\
\hline & & & & 103 & 0.990 & & & 131 & 1.014 \\
\hline & & & & 102 & 0.994 & & & 134 & 1.003 \\
\hline & & & & 116 & 1.008 & & & 138 & 0.999 \\
\hline & & & & 115 & 0.994 & & & 142 & 0.986 \\
\hline & & & & 114 & 0.994 & & & & \\
\hline & & & & 113 & 0.987 & & & & \\
\hline & & & & 117 & 1.002 & & & & \\
\hline & & & & 128 & 0.990 & & & & \\
\hline & & & & 130 & 0.994 & & & & \\
\hline & & & & 133 & 1.004 & & & & \\
\hline & & & & 137 & 1.037 & & & & \\
\hline & & & & 141 & 1.007 & & & & \\
\hline
\end{tabular}

